\title{
The influence of emotion on cognitive control: relevance for development and adolescent psychopathology
}

\author{
Sven C. Mueller* \\ Department of Experimental Clinical and Health Psychology, Ghent University, Ghent, Belgium
}

Edited by:

Gilles Pourtois, University of Ghent, Belgium

Reviewed by:

Alexandre Schaefer, University of Durham, UK

Ulrike Krämer, University of Lübeck, Germany

\section{*Correspondence:}

Sven C. Mueller, Department of Experimental Clinical and Health

Psychology, Ghent University, Henri Dunantlaan 2, B-9000 Ghent,

Belgium.

e-mail:sven.mueller@ugent.be
The last decade has witnessed an explosion of research into the neural mechanisms underlying emotion processing on the one hand, and cognitive control and executive function on the other hand. More recently, studies have begun to directly examine how concurrent emotion processing influences cognitive control performance but many questions remain currently unresolved. Interestingly, parallel to investigations in healthy adults, research in developmental cognitive neuroscience and developmental affective disorders has provided some intriguing findings that complement the adult literature. This review provides an overview of current research on cognitive control and emotion interactions. It integrates parallel lines of research in adulthood and development and will draw on several lines of evidence ranging from behavioral, neurophysiological, and neuroimaging work in healthy adults and extend these to work in pediatric development and patients with affective disorders. Particular emphasis is given to studies that provide information on the neurobiological underpinnings of emotional and cognitive control processes using functional magnetic resonance imaging. The findings are then summarized and discussed in relation to neurochemical processes and the dopamine hypothesis of prefrontal cortical function. Finally, open areas of research for future study are identified and discussed within the context of cognitive control emotion interactions.

Keywords: review, emotion cognitive control interaction, development, anxiety, depression

\section{BRIEF INTRODUCTION TO THEORIES OF EMOTION AND COGNITIVE CONTROL}

Past research has investigated the influence of emotion on a variety of cognitive processes including basic visual (Pourtois et al., 2005; Brosch et al., 2008) and sensory processing (Moratti et al., 2006), memory (Banich et al., 2009), or attentional biases (BarHaim et al., 2007). A longstanding effort has been to understand the basic mechanisms of cognitive control, which indexes our ability to regulate and pursue goal-oriented behavior. A major motivation for this article, and this special issue, has been the assumption that control of such goal-driven behavior is especially required in the presence of emotionally evocative information. Surviving an encounter with a grizzly bear in the woods requires strong inhibitory control to overrule the initial tendency for a flight response, and remain calm and still instead. Thus, how does emotion influence cognitive control? Do all types of emotion, positive, and negative, have the same effect on regulatory processes? Does emotion enhance or impair cognitive control abilities and are these effects short-term or more sustained? The goal of this

\footnotetext{
Abbreviations: ACT, attentional control theory; AMY, amygdala; BD, bipolar disorder; dACC, dorsal anterior cingulate; dIPFC, dorsolateral prefrontal cortex; DMN, default mode network; FFA, fusiform face area; FG, fusiform gyrus; IFG, inferior frontal gyrus; IPL, inferior parietal lobule; IPS, inferior parietal sulcus; MFG, middle frontal gyrus; MNI, Montreal Neurological Institute; Nacc, nucleus accumbens; OCD, obsessive-compulsive disorder; OFC, orbito-frontal cortex; PPA, parahippocampal place area; PTSD, post-traumatic stress disorder; rACC, rostral anterior cingulate; SFG, superior frontal gyrus; SPC, superior parietal cortex; SPL, superior parietal lobule; vlPFC, ventrolateral prefrontal cortex.
}

review is to examine these questions by reviewing studies from the emerging field of cognitive control emotion interactions and the influence of emotion on executive processes specifically. Due to the vastness of the field, this study will not examine the flipside of this approach, i.e., studies that merely concern the regulation of emotion per se.

Although much of this research has been conducted in adults, preliminary parallel research in child and adolescent development is emerging and has provided some intriguing findings. Therefore, a second goal of this review is to integrate these parallel lines of research and examine how experimental studies in adults can inform future directions for developmental cognitive neuroscience and vice versa.

To set the stage and provide a theoretical context within which cognitive control by emotion interactions can be evaluated, the article will begin with very brief introductions into the current state of cognitive control and emotion research. However, it must be noted that these introductions merely serve to provide brief overviews, and therefore, these sections cannot do justice to provide a detailed and balanced account of all theories. Then, the available evidence on cognitive control and emotion interactions will be surveyed, first in adults and then in development. In particular, this survey will examine to what extent emotional influence is common across diverse cognitive control abilities such as working memory, inhibitory control, or task switching and whether this influence is dependent on the type of emotional presentation such as prior mood induction, emotional distraction, or availability of reward. The review will end 
with a discussion of open questions for future research and a brief summary ${ }^{1}$.

\section{THEORIES OF COGNITIVE CONTROL}

Much advance in the field of cognitive control has been made over the last half century and several models at both the theoretical or neuroanatomical level have been proposed (Norman and Shallice, 1986; Fuster, 1997; Smith and Jonides, 1999; Braver and Cohen, 2000; Duncan and Owen, 2000; Stuss and Alexander, 2000; Miller and Cohen, 2001; Petrides, 2005; Banich, 2009). Although a definitive set of executive functions has not been agreed upon, many cognitive skills have been attributed to this category including planning (Koechlin et al., 2000), goal maintenance (Koechlin et al., 1999), task switching (Robbins, 1996; Brass and von Cramon, 2002; Dreher et al., 2002), response conflict, error monitoring, and decision uncertainty (Botvinick et al., 1999; Ridderinkhof et al., 2004), inhibitory control (Aron et al., 2007), and working memory (Wager and Smith, 2003). Through latent-variable analyses, it has been suggested that there are (at least) three different core executive processes, which comprise inhibitory control, the ability to shift (task) sets, and maintenance and updating of working memory (Miyake et al., 2000).

In any case, while most authors would now agree that the lateral prefrontal cortex (PFC) plays a critical role in executive function, models with regards to the specificity of this localization of function have not been without contention (Duncan and Owen, 2000; Stuss and Alexander, 2000; Petrides, 2005; Banich, 2009). While some authors ascribe specific executive functions to particular parts of the brain (Petrides et al., 1993; GoldmanRakic, 1995), others propose a common network of the lateral PFC, which engages across a diverse set of cognitive demands including response conflict, task novelty, working memory delay, and perceptual difficulty (Duncan and Owen, 2000).

Given the variety of theoretical and neuroanatomical models the search for a unifying model of executive function continues. Some models identify particular executive processes with neuroanatomical locations, which are recruited in a sequence ("cascade") of events (Koechlin et al., 2003; Banich, 2009). For example, in the "cascade-of-control model" (Banich et al., 2009) top-down biases toward task-relevant processes are established in the posterior region of the dIPFC and passed on to the mid-dlPFC, which selects the most relevant out of the actively maintained task representations. In the next step of this cascade, the posterior portion of the dorsal ACC selects the appropriate response among the available response options and so on. By comparison, and in-line with other models (Botvinick et al., 1999; Ridderinkhof et al., 2004), the anterior dorsal ACC monitors and evaluates the responses and, in case of an occurring error, dACC signals back to the posterior dIPFC for greater control requiring re-initiation of certain steps of the cascade of events. The central tenet of such a cascade model is that cognitive operations are executed sequentially, and, if not accomplished adequately at a previous step, these operations require to be processed at a subsequent step. As the search for an

\footnotetext{
${ }^{1}$ Note that despite historical differences in usage between the terms "executive function" and "cognitive control," both will be used interchangeably throughout the article to refer to all brain regions involved in such functioning.
}

integration of theory and neuroanatomy in cognitive control continues, the aim to specify the role of emotional processes during cognitive control will either facilitate (at best) or further complicate (at worst) this endeavor. The next section will provide a brief glance at current thoughts in emotion theory.

\section{PROCESSING AND REGULATING EMOTIONS}

Human feelings and emotions have long occupied the thoughts of scientists and philosophers alike. Several cognitive and noncognitive theories of emotions have been proposed (cf. Dalgleish, 2004). Among the cognitive theories, appraisal theories (e.g., Arnold, 1960; Frijda, 1988; Lazarus, 1991; Scherer, 1999; Roseman and Smith, 2001) postulate that emotions are caused (elicited) by appraisals, i.e., subjective evaluations of occurring events. For instance, the final acceptance of an article in a journal could give rise to several emotions in the author including joy, pride, relief, or content. The precise emotion, however, will depend on the specific appraisal by that individual. By virtue of mediation between the event and the emotion, appraisal theories provide a multi-level approach, which allows for subtle variations between and within individuals as to which emotion will be elicited at which specific moment in time and at which specific situation. Within that framework, other authors propose degrees of motivation and emotional behavior that depends on the immediacy and severity of relevant change from the current state of events (e.g., Roseman and Smith, 2001). For example, the distance to the deadline for submission of said article may determine whether the author approaches the manuscript with "cold" but motivated and goal-driven behavior to finish the paper within the next month or may experience "hot" emotion and react with frozen shock and readiness to jump into action by the realization that the deadline is a mere $48 \mathrm{~h}$ away.

By contrast, biologically based, non-cognitive theories of emotion propose a direct relationship between the event, the emotion, and the physiological or neural state. Among the most well-known is the James-Lange theory (James, 1884; Lange, 1885), which proposes that emotions are mere experiences of the change of the bodily state. In such a case, the experience of the physical changes involved in fleeing from a threatening stimulus would be equated with the emotion of fear. Both sets of theories have led researchers to hypothesize different parts of the brain to be involved in the processing of emotion. These different neural foci include the amygdala (LeDoux, 2000), the septo-hippocampal system (SHS; Gray and McNaughton, 2000), the orbito-frontal cortex (OFC; Rolls and Grabenhorst, 2008), the ventromedial PFC (Damasio, 1996), or the brainstem circuitry (Panksepp, 1998). For example, in Damasio's (1996) "somatic marker hypothesis," the ventromedial PFC plays a strong role in processing those physiological changes of the body, which have previously been tagged as emotionally significant events. Other researchers have attributed a prominent role to the OFC in emotion processing, in particular as it pertains to motivational aspects of behavior vis-a-vis emotional learning of stimulus-reward associations (Rolls and Grabenhorst, 2008). That line of research assesses and classifies motivational valence of a stimulus as being positive and rewarding or negative and punishing. Yet another group of researchers highlight the amygdala as a central hub in the processing of fear (LeDoux, 2000). These investigators suggest two routes of emotional processing; a 
fast, direct route from the thalamus to the amygdala, which can process crude information quickly and without awareness while a second, indirect and slow route uses a thalamo-cortical-amygdala pathway. This pathway allows a more fine-grained and conscious analysis of the stimulus. However, this distinction has recently come under criticism. Although Pessoa and Adolphs (2010) also suggest two central hubs, the amygdala and the pulvinar, they emphasize strong communication of these regions with broad cortical and subcortical regions. In addition, these authors suggest equally fast processing of affective and non-affective visual information.

Theories of emotion regulation have particularly focused on the dlPFC and the cingulate system and their role in modulation and controlling an emotional response (Bush et al., 2000; Ochsner and Gross, 2005). In particular, these theories distinguish between the dorsal ACC, which is involved in cognitive control, and the rostral ACC, which finds its role in regulating emotions (e.g., Bush et al., 2000). Parcellation of the ACC into a rostral and dorsal part, in turn, has come under scrutiny from recent reviews that suggest an integration of reinforcers and goal-directed behaviors within the "anterior mid-cingulate cortex (aMCC)" (Shackman et al., 2011).

Regardless of the type of brain system involved in affective processing, some investigators have pointed to a hemispheric divide when processing emotions. Following earlier authors (Mills, 1912), the work of Davidson (1995) suggests different specialization for specific emotion processing in the two hemispheres. In their theory, negative emotions are predominantly processed by the right hemisphere, while positive emotions are processed by the left hemisphere. However, this hypothesis has also been challenged by a meta analysis of functional imaging studies that points toward a more complex picture including regional specificity (Wager et al., 2003).With these conceptual distinctions in mind, the next section will review the available evidence of emotional influences cognitive control processes.

\section{COGNITION BY EMOTION STUDIES IN ADULT VOLUNTEERS FINDINGS IN HEALTHY ADULT VOLUNTEERS}

Studies in neurologically healthy adults have used several methodologies and experimental paradigms including behavioral investigations, event-related potentials (ERP), repetitive transcranial magnetic stimulation (rTMS), and functional magnetic resonance imaging (fMRI), $n$-back tasks, recency probes task, flanker and stop-signal tasks, to task switching, delayed item working memory, go/no-go tasks, antisaccade, Simon, and Stroop tasks (Table 1).

\section{Behavioral and psychophysiological evidence}

Behavioral studies have provided the groundwork to establish the paradigms that can be used to demonstrate emotional impact on cognitive control processes. This line of research has shown consistent impairment of cognitive control during concurrent, task-irrelevant emotional processing. High emotional distracting stimuli, for example, impaired performance during task switching, inhibitory control tasks, working memory, or target detection tasks (Table 1). Traditional psychophysiological measures have provided valuable information regarding the neurobiological and neurophysiological processes underlying such interference effects. For instance, the startle response, i.e., an involuntary response to an unexpected and sudden stimulus, is closely linked to affective processing (Lang et al., 1990). Using this startle reflex during a standard flanker task, Hajcak and Foti (2008) reported that startle response magnitude was larger after errors than after correct responses. They suggested a close connection between the emotional regulatory system and cognitive control processes such as error monitoring. Other psychophysiological indices of control processes are also sensitive to emotional modulation. A larger fronto-central No-Go P3 amplitude has been reported in a positive relative to a negative context during a go/no-go task with incidental emotional stimuli in the background (Albert et al., 2010). Consistent with this finding, reaction times (RT) to Go trials were faster in the positive relative to the negative or neutral context. These data suggest that psychophysiological responses can peg the influence of defensive reflexes and positive context on cognitive control processes such as error monitoring and inhibition.

\section{Evidence from fMRI}

Functional neuroimaging studies have provided important information on the neural underpinnings of these effects, thus complementing psychophysiological findings. For example, Gray et al. (2002) induced a positive, negative, or neutral emotional state with short video clips before participants completed two different 3-back working memory tasks, one with verbal and one with facial stimuli. With verbal stimuli, the dorsolateral PFC [Brodmann area (BA) 9] was activated more for unpleasant emotional state relative to pleasant state, while with face stimuli, BOLD responses were increased for pleasant relative to unpleasant states. In another study negative but not positive or neutral mood resulted in increased error rates during a Simon task (Sommer et al., 2008). Concurrent with this behavioral finding, negative mood was associated with reductions in lateral PFC in incompatible when compared to compatible trials. While these data suggest that lateral PFC activation to working memory or conflict demands is sensitive to negative mood state, other studies have focused on the influence of attentional load on emotion processing (Pessoa et al., 2005; Lim et al., 2008; Bishop, 2009).

In a target detection task, letter arrays consisting of the same distracters (low attentional load) or different distracters (high attentional load) were displayed across emotionally valenced faces (Lim et al., 2008). When threat faces were compared to neutral faces in the low attentional load condition, increases in activation were apparent in several regions including the SPL, MFG, dACC, and FG. By contrast, this effect was absent during the high attentional load conditions. In particular, amygdala activation followed the same pattern as in the other regions suggesting vulnerability of this region to changes in top-down influences of cognitive load. In opposition to these findings is a study in which neutral or negatively valenced IAPS pictures were presented before a simple or a complex arithmetic problem (Van Dillen et al., 2009). Here, right amygdala activation was decreased during negative images during the complex task relative to the simple task. Similarly, the high but not low load negative condition led to increased activations in the same regions as in Lim et al. (2008), namely in the dlPFC and SPC. One possible difference between these two studies that might account for the discrepancy in findings is that emotional stimuli were present prior to the task in Van Dillen et al. (2009) while 


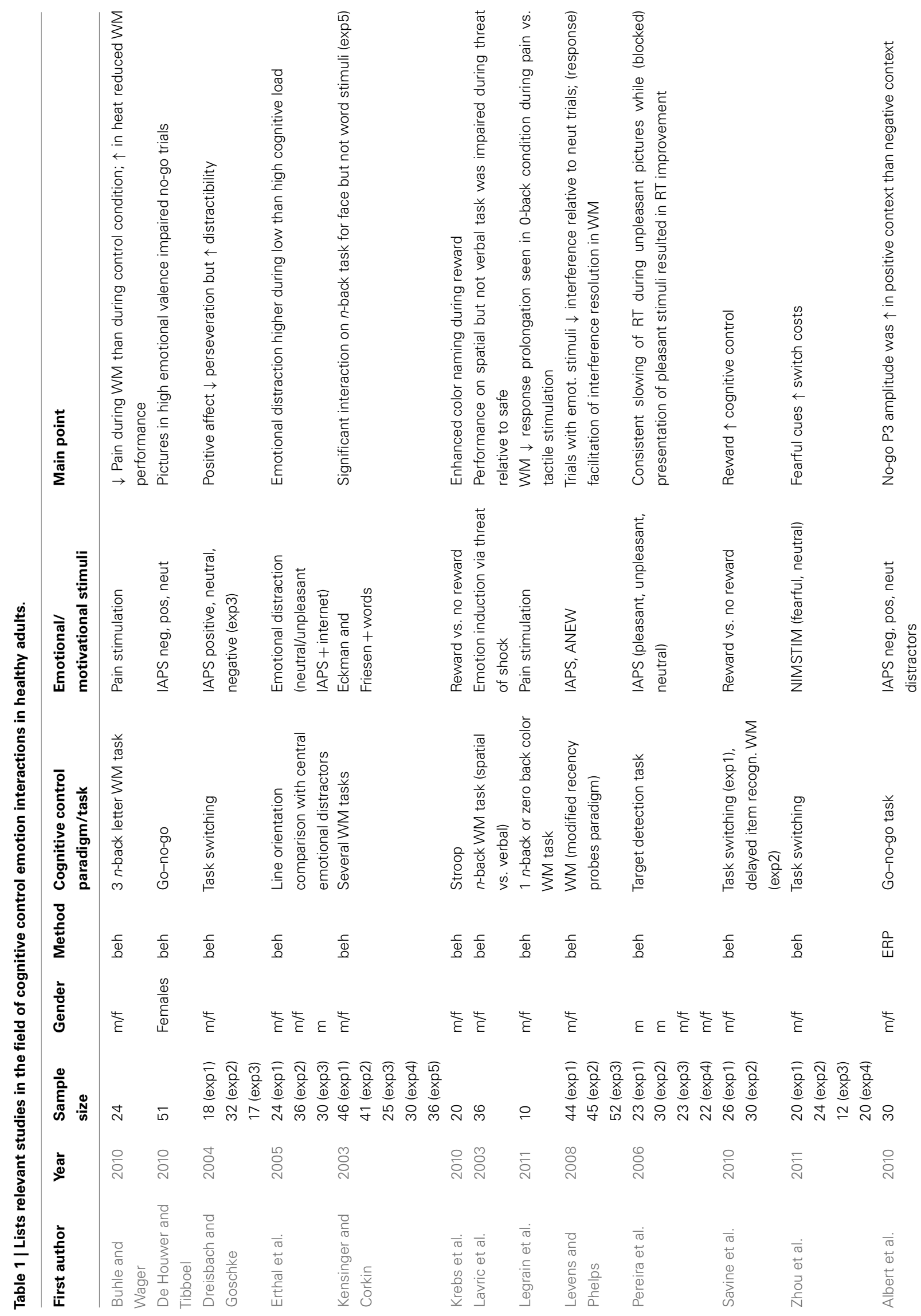



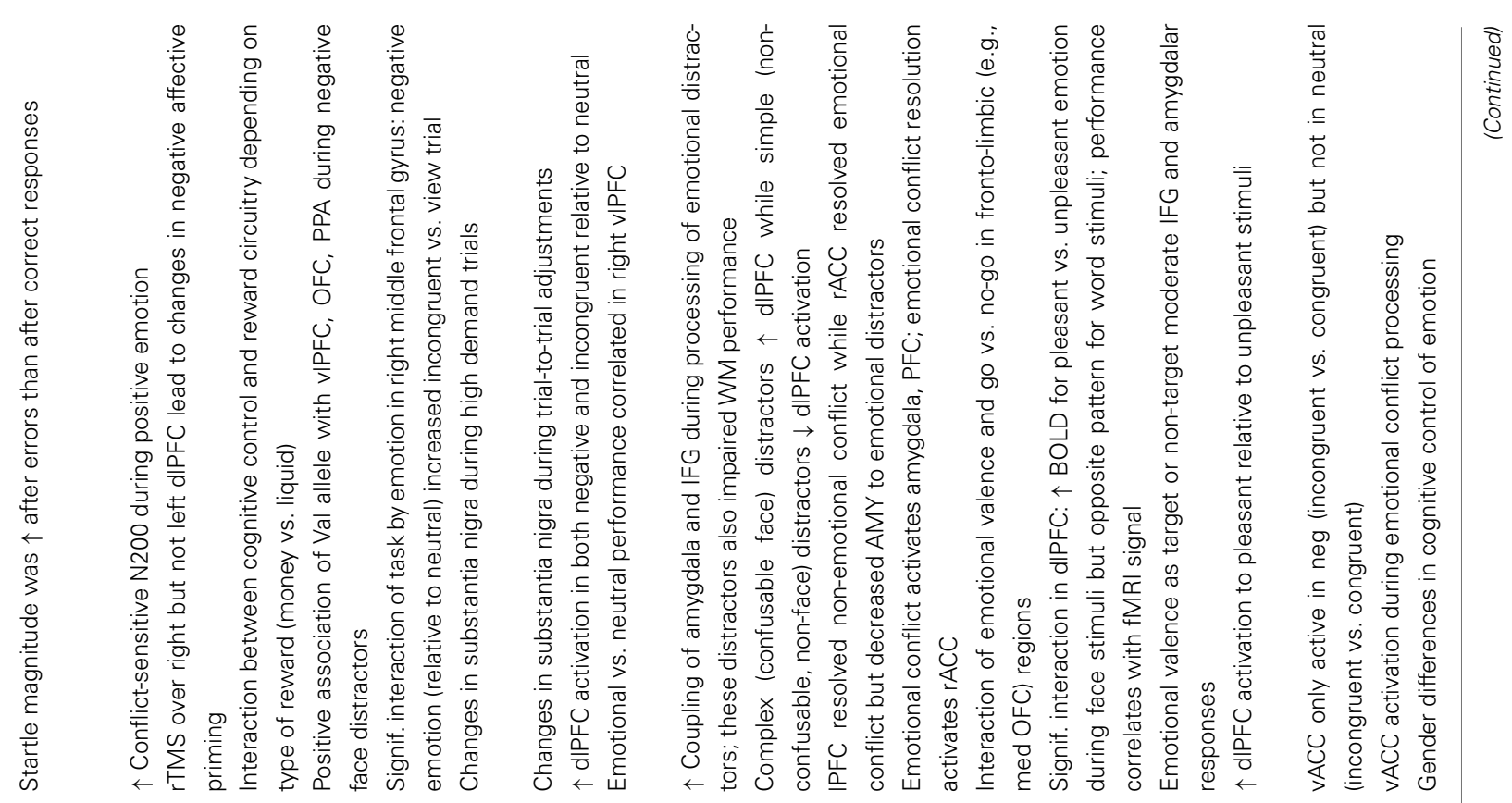

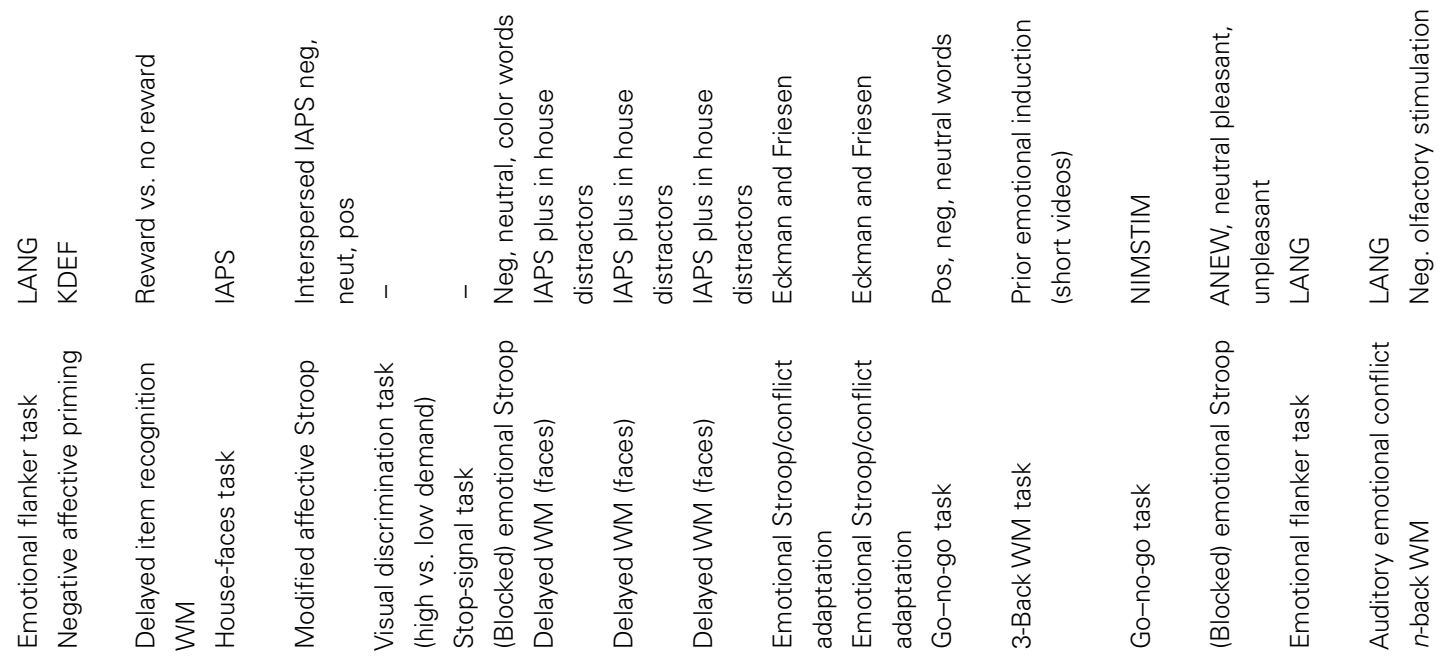

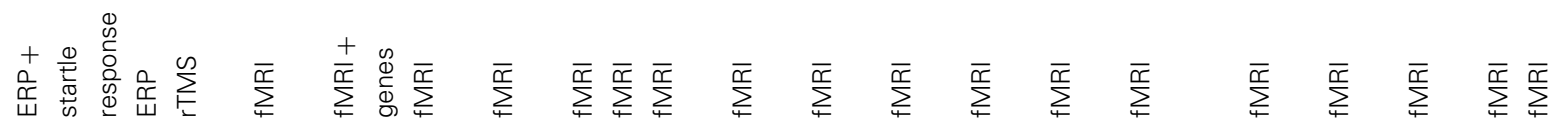

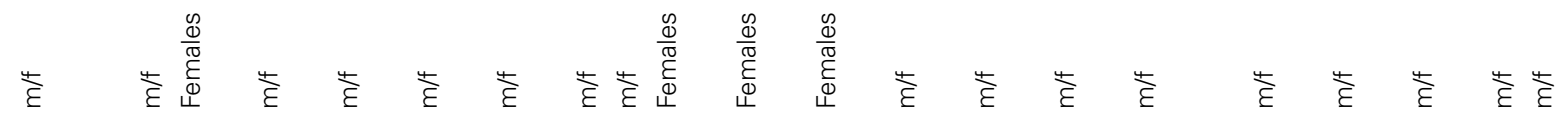

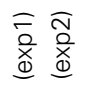

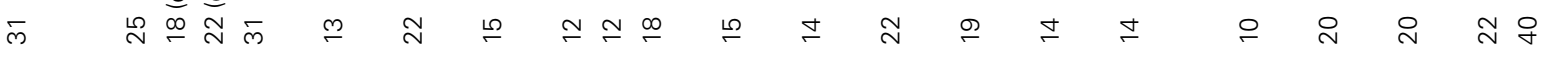

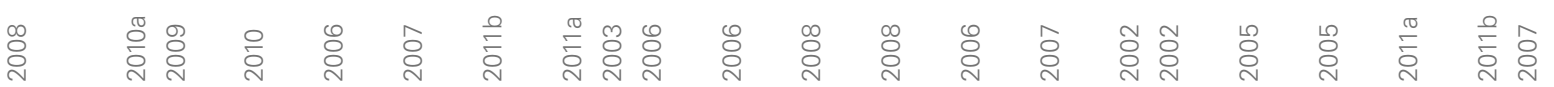

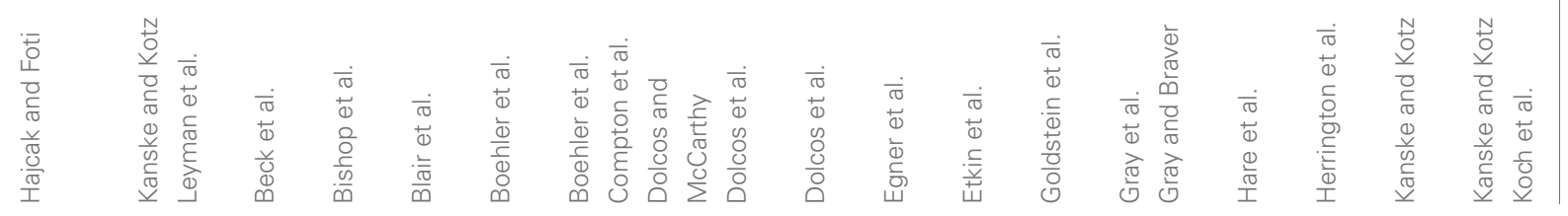




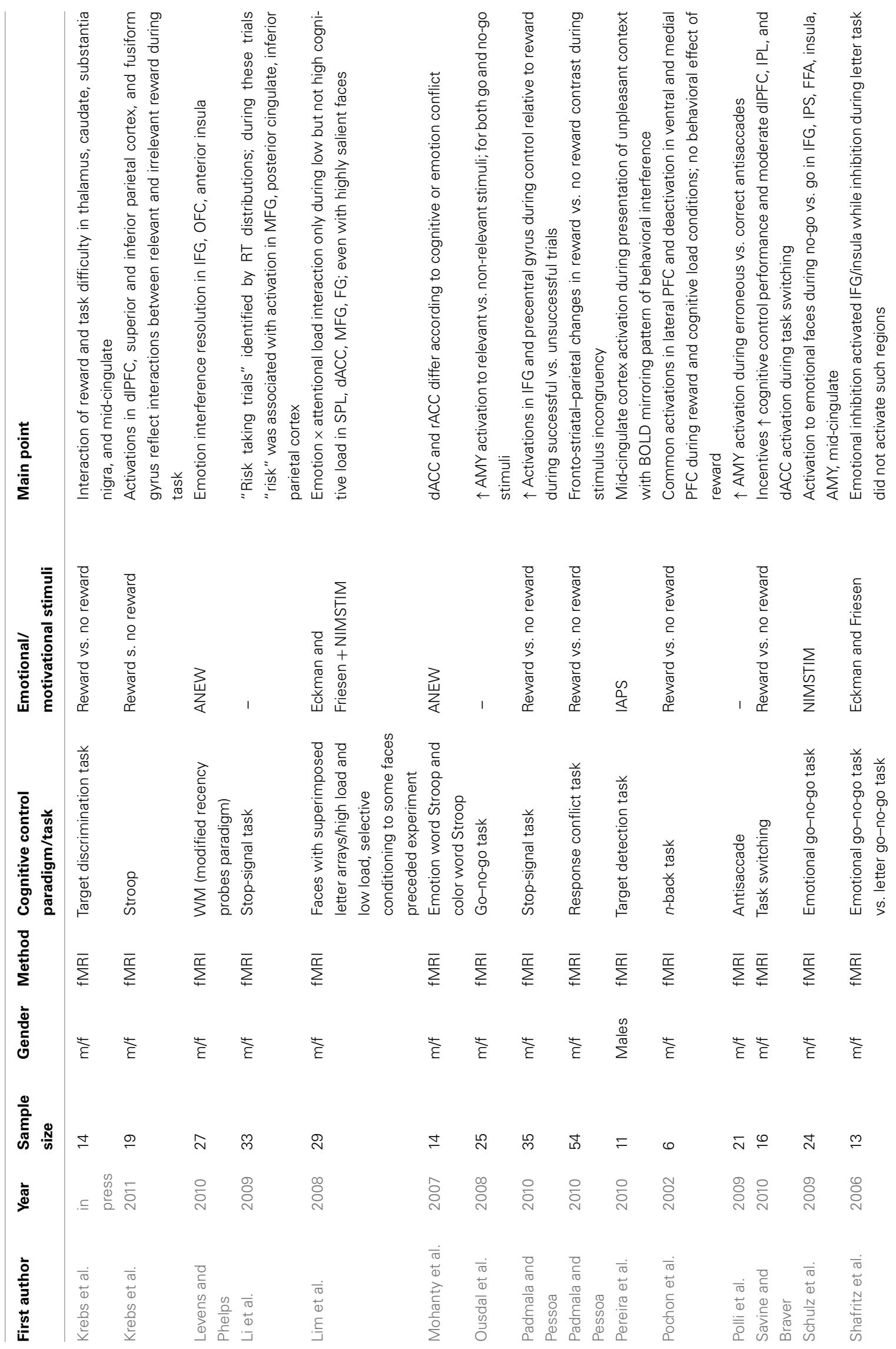




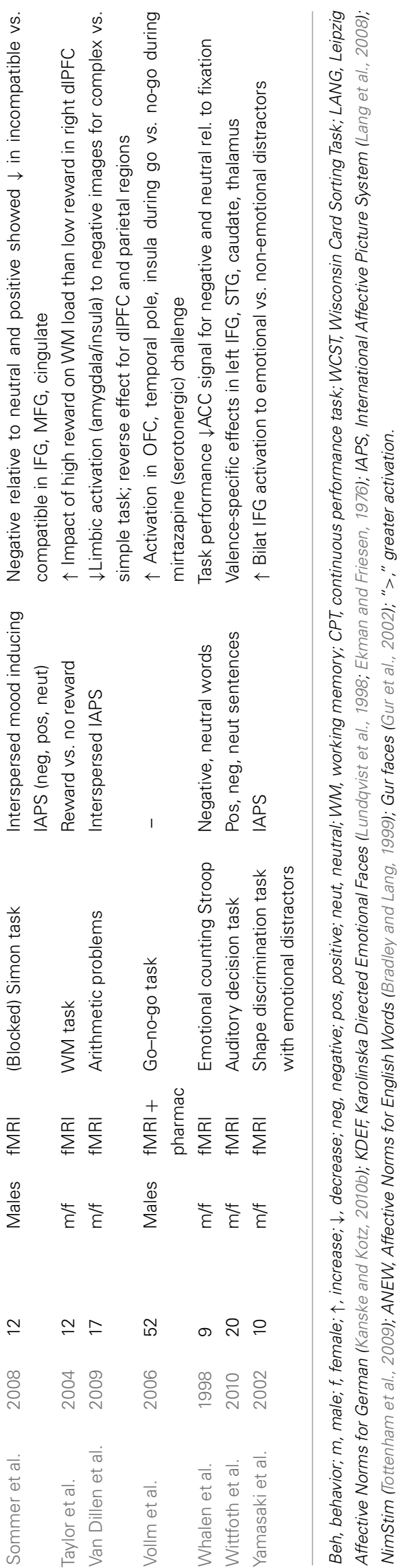

they occurred simultaneously in Lim's study. While the type of attentional task may also have played a significant role, these findings provide supportive evidence that attentional load moderates emotional processing.

Inhibitory control processes are also vulnerable to modulation of emotional valence. The pars opercularis and pars triangularis of the IFG evidenced reductions on no-go trials in response to happy but not sad or neutral faces (Schulz et al., 2009). An effect for sad (but not happy or neutral) stimuli, on the other hand, was observed in the posterior insula. Previous studies have highlighted different responding of neurocircuitry to different emotions (e.g., Vytal and Hamann, 2010). An interesting question related to this finding and within the context of emotion cognition interactions would be the sensitivity of distinct cognitive control regions to specific emotional valences. In other words, would happy or fearful emotion recruit the IFG but sad or angry emotion other areas?

If emotional valence exerts effects on inhibitory control in cognitive control workhorses such as the IFG, a pivotal question would be whether the reverse can also be observed, i.e., evidence of executive control processes in emotional hubs such as the amygdala. In their psychophysiological study, Hajcak and Foti (2008) had suggested a connection between defensive reflexes and error processing. Given the amygdala's role in the neurobiology of fear (LeDoux, 2000), an ideal proof-of-concept would be to demonstrate presence of such error processing in this region. Indeed, in an antisaccade task with strong non-emotional inhibitory control requirements, amygdala activation was increased during erroneous relative to correct antisaccades (Polli et al., 2009). Further corroborating evidence comes from other cognitive control studies void of an emotional context, which have examined variations in RT distributions. For example, in a stop-signal task, RT to "go" trials on trial $(n)$ can either be faster or slower than RT on the previous trial $(n-1)$. Li et al. (2009) argued that this variability in performance may originate from participant's anticipation of a looming "stop" trial. Thus, responding faster in the presence of a potential "stop" trial is "risky" and may lead to an error whilst a slower response may show "risk-aversion." Comparisons between individual fast and slow responses relative to the mean of all "go" trials in Li's study revealed heightened amygdala and vmPFC activations during fast "risky" trials relative to slow "non-risky" trials. Evidence of error processing or adaptive changes in trial-to-trial fluctuations during non-emotional tasks would support the idea of an involvement of regions traditionally associated with emotion in cognitive control. Intracranial recordings in patients undergoing invasive surgery complement these research lines. Two separate intracranial recording studies have documented modulation of subcortical structures such as the Nucleus Accumbens (Münte et al., 2008) or the amygdala (Pourtois et al., 2010) during error monitoring processes whilst performing flanker or go/no-go tasks. These data support the idea of involvement of regions traditionally associated with emotion in cognitive control.

\section{From "hotspots" to "patterns of activation": evidence from functional connectivity}

Recent trends in the cognitive neurosciences have witnessed a shift from a localization-oriented analysis approach to examining the pattern of activations between brain regions. Analysis of 
such functional connectivity has offered intriguing insight into the influence of emotion on cognitive control from a brain pattern perspective. As is well-known, during the color naming condition of the Stroop task, cognitive interference is created by the actual meaning of the presented word relative to the font it is presented in (e.g., the word red presented in blue font). Using this principle, Banich and colleagues modified the Stroop task to present words that interfered at an emotional level (e.g., war) when participants were required to name the font color (Mohanty et al., 2007). They reported that during conflict trials, reactivity of both dorsal and rostral ACC predicted amygdala activation. By comparison, only dorsal ACC predicted dlPFC activation. A different team of researchers created emotional conflict by superimposing words of emotional states on congruent or incongruent emotional facial expressions (e.g., the word "happy" presented on a fearful face). Functional connectivity analyses during this task revealed a negative coupling between the rACC and the amygdala, which indicated a decrease in amygdala activation with an increase in rACC activity (Egner et al., 2008). In addition, the fact that lateral PFC was positively coupled with the fusiform face area (FFA) during non-emotional conflict resolution but negatively during emotional conflict resolution attributes a critical role of valence to connectivity patterns.

\section{Impact of motivation on cognitive control}

As noted in the introduction, some theories discriminate between emotional and motivational processes in emotion (Plutchik, 1962), while others argue that both processes are necessary to fully account for goal-driven behavior (Roseman, 2008). An intriguing question arising from these theories is to what extent influences of these two emotional systems on cognitive control abilities might be similar to each other. Studies in the category of motivational processing have examined the impact of reward (vs. no reward) on a variety of executive processes including the stop-signal task, the task switching paradigm, working memory, antisaccade performance, or the Stroop task (Table 1).

In an inhibitory control task, reward, by virtue of monetary incentive, interacted with stop-signal task performance in several brain regions (Padmala and Pessoa, 2010). Particularly when no incentive was provided, the left dlPFC responded more actively to successful vs. unsuccessful trials. This difference was reduced during the incentive condition. In stark contrast to these data are the results of another imaging study, in which monetary incentive increased the BOLD response in the left dlPFC during task switching (Savine and Braver, 2010). This response was also positively correlated with the incentive benefit of improved RTs during this condition. These studies on motivation suggest that positive incentive such as monetary reward can influence responding of the lateral PFC.

However, one aspect that may modulate the strength of this response could be the potency of the reward. Non-human primate studies commonly utilize primary reinforcers such liquids (e.g., juice; Bermudez and Schultz, 2010; Kobayashi et al., 2010). Studies in humans, by comparison, frequently rely on secondary reinforcers such as monetary incentive (Padmala and Pessoa, 2010; Savine and Braver, 2010). The critical distinction between primary and secondary reinforcers is that while the former is immediately rewarding in itself, the latter can be collected and later exchanged for a rewarding stimulus (e.g., ice cream after a long day of revisions). Recently, Beck et al. (2010) contrasted primary (liquid) vs. secondary (money) reinforcers while volunteers performed a working memory task. Although behavioral performance improved with both types of reward, a double dissociation was apparent in the underlying neural circuitry. Consistent with the findings by Padmala and Pessoa (2010) and Savine and Braver (2010), monetary reward increased the hemodynamic response in the dlPFC. In contrast to these prior findings, the primary reinforcer evoked neural activation in striatal regions and the amygdala. Taken together, these data seem to indicate that some cognitive control circuitry such as the dlPFC is commonly moderated by emotional as well as motivational stimuli, while other executive structures such as the basal ganglia (striatum) are preferentially sensitive to motivational aspects of goal-driven behavior.

\section{Let's talk about sex (in cognition emotion interactions)}

Regardless of the distinction between emotional vs. motivation behavior, the previous sections have focused on manipulations that changed from trial-to-trial. One critical question in emotion research is to what extent emotional interference may be driven by inherent differences between participants. One such critical factor, especially with relevance to preponderance for different forms of psychopathology, is biological sex. To avoid potential sex-driven confounds, some studies have elected to recruit exclusively female or male groups of participants (cf. Table 1). However, directly contrasting men and women may reveal important differences in how emotion may impact executive control between the genders. In one such endeavor, sex differences were explicitly investigated using aversive olfactory stimulation to induce negative mood while participants performed a working memory task (Koch et al., 2007). Sex-specific interactions between working memory and negative emotion revealed stronger activation for females relative to males in emotion networks including the OFC (BA11) and the amygdala. By comparison, males exhibited stronger activations than females in a wide temporo-parietal-occipital network. These authors suggested (Koch et al., 2007) that during concurrent cognitive control demands within a negative emotional context, perceptual-cognitive processing was predominant in men, while the processing of emotions was prioritized in females. To foreshadow findings from the second part of this review, these results in adults are consistent with documented sex differences in developmental groups (Tottenham et al., 2011) and propose sex-specific processing of emotions during cognitive control tasks making it a critical variable in cognition emotion interaction research.

\section{Genetic and neuropharmacological contributions}

Mounting interest in genetic neuroimaging has motivated researchers to examine the impact of different genotypes on cognitive control and their relation to emotion processing. For example, while neurotropic (e.g., BDNF) or serotonergic (e.g., 5-HT) genes contribute to mood and anxiety disorders (Martinowich et al., 2007), dopaminergic (e.g., COMT) genes have been implicated in cognitive control (Barnes et al., 2011). In a small sample of volunteers, Bishop et al. (2006) reported an influence of the COMT 
genotype on the attentional matching task during emotional distraction. In the task, also known as the house-faces task, participants were required to determine whether two presented images along a horizontal or vertical dimension were identical or not. However, the other two images presented at the unattended location either contained neutral or emotional images. Presence of the high dopamine activity val/val polymorphism correlated significantly with BOLD signal change in the negative relative to neutral emotional contrast in several regions including the vlPFC, the OFC, and the parahippocampal place area (PPA). Following a similar reasoning, Vollm et al. (2006) provided healthy male participants with the serotonergic drug Mirtazapine to investigate the impact of 5-HT on inhibitory control. Here, the drug modulated inhibitory function in the lateral OFC, the temporal pole, and the insula. Although the influence of the drug was also assessed on a separate reward task in the same study, the interaction of reward on inhibitory control was unfortunately not explicitly examined. Whilst tentative, these promising data indicate effects at the neurotransmitter level on OFC function during emotional challenges.

\section{IMPACT OF MOOD AND PERSONALITY ON EMOTION AND COGNITIVE CONTROL}

The above studies have revealed that responses in goal-driven behavior during emotional challenges may differ based on gender or genetic make-up. Therefore, it seems likely that not only transient emotional responses (e.g., surprise, fear) could impact cognitive control, but also sustained variability in mood or personality of the individual. This section reviews such variation in individual differences (Table 2).

\section{Anxiety and cognitive control}

At some point in our lives, individuals may experience shorter or longer periods of anxiety. According to Eysenck et al. (2007), "anxiety is an aversive emotional and motivational state occurring in threatening circumstances" (p. 336). However, in addition to the state anxiety at a particular moment in time, an individual can also be characterized on how anxious they feel in general, or their level of trait anxiety. Their attentional control theory (ACT) was developed to make specific predictions on how levels of anxiety within the healthy population will impact cognitive control (Eysenck et al., 2007). One central axiom of ACT is that processing effectiveness, which describes the quality of task performance (response accuracy), is less affected by anxiety than processing efficiency, i.e., the relationship between processing effectiveness and cognitive effort exerted during the task (RT). In particular, being in a state of anxiety reduces attentional control and thus processing efficiency. Distracting and salient threat-related information draws additional processing resources away from goal-oriented attention further reducing effective processing. In a series of behavioral studies to probe ACT, Derakshan and colleagues examined the impact of subclinical anxiety on cognitive control processes (Ansari et al., 2008; Derakshan et al., 2009a,b). In a traditional task switching design, participants switched between or repeated basic arithmetic operations (Derakshan et al., 2009b). These arithmetic problems were either simple (addition, subtraction) or complex (division, multiplication). During switching, when cognitive control levels were high, performance was slowed in high anxious but not low anxious participants, an effect that was particularly the case for complex but not simple mathematical operations. In another study, she investigated processing of emotional faces during inhibitory control by virtue of the antisaccade task (Derakshan et al., 2009a). Consistent with the first study and ACT, processing efficiency, as seen in prolonged latency, was reduced in high anxious relative to low anxious participants. By comparison, processing effectiveness, i.e., antisaccade error rates, were less affected.

Subjective levels of anxiety have also been shown to influence psychophysiological correlates of cognitive control. The errorrelated negativity (ERN) component of the ERP commonly shows an increased negativity over central scalp after an error is committed relative to correctly executed trials (Falkenstein et al., 1990; Gehring et al., 1993). Using a two-dimensional, non-emotional (color or orientation judgments) go/no-go task, Aarts and Pourtois (2010) recently documented that the amplitude of the ERN was larger in high anxious vs. low anxious subjects. Similarly, Amodio et al. (2008) examined differences in personality on a go/no-go task. In his study, higher levels on behavioral inhibition (BIS) were associated with larger N2s and ERNs during no-go trials. Higher scores on the behavioral approach system (BAS), on the other hand, were associated with greater left-sided frontal asymmetry. These data are consistent with the findings by Hajcak and Foti (2008), who had found that the magnitude of the ERN predicted the degree of the defensive reflex during erroneous responses. Taken together, these data suggest that high levels of anxiety or BIS moderate error-related processing.

As alluded to earlier, some researchers have attributed different roles of the left and right hemispheres in processing positive and negative emotions (Davidson, 1995). Engels et al. (2007), for instance, asked participants to perform a (blocked) emotional Stroop task with neutral, pleasant, and unpleasant words while they underwent fMRI. A large cluster of the left but not the right lateral frontal cortex (BAs 9, 44, 45, 47) became visible during negative words relative to neutral words. However, this effect was further moderated by anxious state such that participants scoring high on anxious apprehension showed this effect but not participants having high levels of anxious arousal or low anxious subjects. By comparison, anxious arousal subjects showed right lateralized inferior temporal gyrus activations in the negative relative to neutral contrast. Similarly, undergraduates scoring high on depressive symptoms also showed right temporal gyrus activations for processing of unpleasant words in an emotional Stroop task and, conversely, a leftward lateralization for pleasant words (Herrington et al., 2010). While these studies may suggest a hemispheric divide, an earlier-meta analysis of 65 imaging studies suggests a more complicated picture that includes region-specificity and effects in lateralized processing of emotions (Wager et al., 2003).

Rather than examining emotional valence on lateralized processing within the same task, another approach is to test the effects of valence on different tasks that engage either the left or right hemisphere. One example would be the processing of verbal information by the left and spatial information by the right hemisphere (Smith and Jonides, 1999). Unfortunately, findings in this line of research have not been without contradictions either. Gray (2001) 


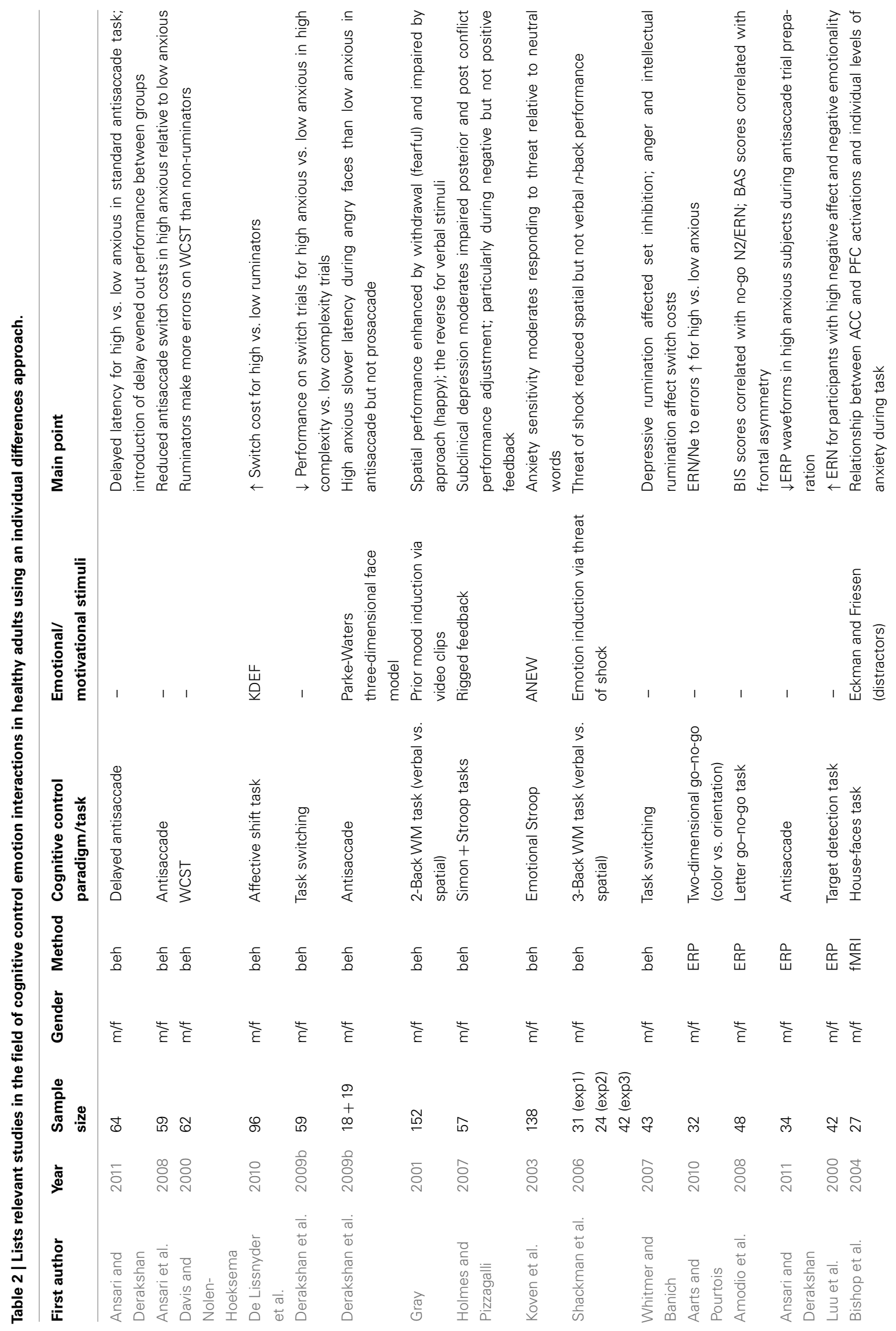



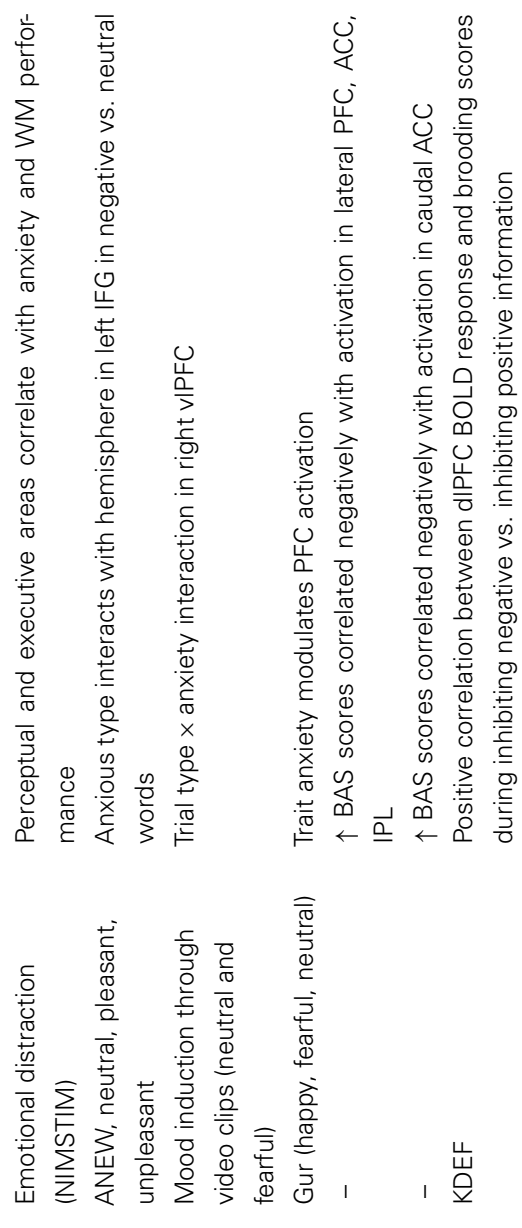

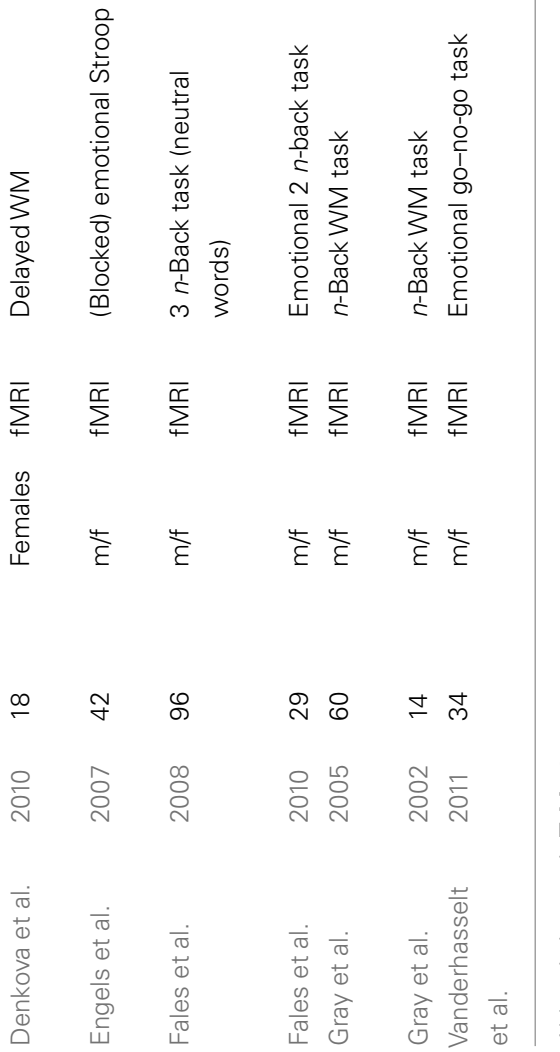

on the one hand, and Shackman et al. (2006), on the other hand, used similar variations of the $n$-back working memory task with a perceptual/spatial variant and a verbal variant. Gray induced mood in participants through affective video clips before the two different 2-back working memory tasks. On the perceptual version, spatial performance was improved by previous encounter with fearful stimuli and impaired during happy context blocks, while the reverse, impairment during fearful and improvement during happy conditions, was true for the verbal task. Importantly, these findings were strongest for subjects with low cognitive control (high error group). By stark contrast, using a similar design and methodology, Shackman et al. (2006) found that threat of shock (i.e., fearful condition) reduced performance on the spatial task but not the verbal task. Moreover, this was particularly the case for participants with high levels of cognitive control (low error group). These findings were replicated in a second experiment of the same study in high anxious subjects (high BIS scores) but not in low anxious subjects. A third study using the threat of shock procedure also reported impaired performance on the spatial but not verbal $n$-back task and a positive association between anxiety levels and performance impairment (Lavric et al., 2003). While these findings support the idea of a differential emotional impact on tasks tapping into different cognitive domains, future research will need to clarify to what extent these contradictory findings may have been driven by individual differences in cognitive control abilities (high vs. low performers) or methodology (introspectively induced emotion vs. continuous threat of physical shock).

Leaving hemispheric contributions on their respective sides, so-called resting-state fMRI studies have documented that a state of anxiety modulates brain rhythms during periods of rest (Zhao et al., 2007; Liao et al., 2010). Neural circuitry usually activated during such periods of rest has also been described as the default mode network (DMN). Recent enquiry has begun to address the impact of anxiety on the engagement of the cognitive control network for a particular task when changing from the "idle" state of the DMN. In a large fMRI study ( $n=96)$, Fales et al. (2008) induced mood in high anxious and low anxious participants prior to an emotionally neutral 3-back working memory task. High anxious participants showed a lower level of sustained activation in the DMN than low anxious participants and this group also showed increased activation of the right vlPFC (BA47) during trial-related engagement. Such preliminary evidence might suggest that the neural activation during rest associated with a particular mood state may be predictive of subsequent engagement of cognitive control. Future study will have to challenge such a conjecture.

\section{Executive deficits in depression}

Similar to theories in anxiety, models in mood disorders have postulated a critical involvement of executive function processes in the development and maintenance of depression (Joormann, 2010). Joormann (2010) proposed that, in depressed persons, a deficit in being able to regulate mood during the presentation of negatively valenced material within working memory leads to impairments in cognitive control. According to the model, a negative event might induce negative mood, which in turn activates negative cognitions. Patients vulnerable to depression may linger ("ruminate") 
on these negative cognitions, thus preventing that this material can be expelled from working memory to free processing resources.

Some studies have examined dimensional measures of depression-linked traits on cognitive control (Holmes and Pizzagalli, 2007; De Lissnyder et al., 2010). Holmes and Pizzagalli (2007) investigated the impact of subclinical depressive symptoms on non-emotional Simon and Stroop task performance. However, performance feedback was rigged such that subjects were presented with positive or negative feedback regardless of their actual performance. Participants with increased depressive traits evidenced impaired adjustment in RT on trials following an error (Simon task) or conflict (Stroop task), especially during negative but not positive feedback. However, it should be noted that high and low depressive symptom groups did not differ on the main variables of congruency or conflict suggesting no global impact on performance. Rather, these data show that subclinical depressive symptomatology may moderate subtle trial-to-trial behavioral adjustments.

Studies in patients with mood disorders including major depressive disorder (MDD; Harvey et al., 2005; Joormann and Gotlib, 2008; Vasic et al., 2009; Levens and Gotlib, 2010), Mania (Elliott et al., 2004), or bipolar disorder (BD; Wessa et al., 2007) are consistent such proposals. These studies have found perturbed activations in lateral frontal circuitry such as the IFG, MFG, or SFG during emotional go/no-go tasks (Elliott et al., 2004) or emotionally neutral $n$-back tasks (Harvey et al., 2005). In addition, a connectivity study in MDD patients during a working memory task revealed perturbations in functional connectivity in the ACC (BA 24/32) and left dlPFC (BA9/46) and vlPFC (BA44; Vasic et al., 2009). Taken together, these data suggest vulnerability of the lateral PFC to negative mood that spans across several executive functions including working memory and response inhibition.

However, an often-noted constraint of fMRI methodology more generally is that it is limited in its capacity to allow inferences on causal relationships between behavior and patterns of activation in the brain. Yet, critical questions regarding the causality and directionality of mood and cognitive control remain untouched. Provocatively asked, is reduced cognitive control a risk-factor for a mood or anxiety disorder or does having an affective disorder cause reductions in cognitive control? One possible way to address these issues is by use of invasive technology such as brain stimulation. rTMS has been used successfully to disturb cognitive performance by discharging neurons in the cortex and is thus ideally suited to examine lateral PFC function (Walsh and PascualLeone, 2003). In a series of studies, Vanderhasselt et al. (2009a,b), administered rTMS over the left dlPFC in patients with MDD while these performed a switching task between different modalities (auditory, visual). These studies revealed two findings. First, a single session of rTMS improved attentional control. Second, behavioral control was also improved in treatment responders but not non-responders after 2 weeks of rTMS therapy. These data point toward TMS as a possible tool to further investigate the contribution of perturbations of cognitive control to mood and anxiety disorders.

The previous sections provided an updated overview of the current state of research in emotion and cognitive control interactions. This overview can now be used to assess similar progress on this topic in developmental cognitive neuroscience.

\section{DEVELOPMENTAL (COGNITIVE) NEUROSCIENCE}

Over the past 10 years, developmental cognitive neuroscience has blossomed to a major field of enquiry. Within the present context, this line of research can provide valuable knowledge of the developmental contribution to the interplay between cognitive control and emotion in the immature organism. Anatomically, longitudinal studies have delineated distinct developmental trajectories for individual brain regions such as a slow rate of PFC maturation (Giedd et al., 1999; Paus et al., 1999; Gogtay et al., 2004). If the PFC and other regions such as those of the limbic system evidence different developmental trajectories, then one would expect task performance and behavior to reflect these differences. Indeed, it has been proposed that the increased risk taking of teenagers relative to children and adults originates from discrepancies in PFC and striatal development (Dahl, 2004; Ernst et al., 2006; Somerville and Casey, 2010). These authors (Ernst et al., 2006; Somerville and Casey, 2010) argue that the relatively faster development of reward-related striatal neurocircuitry and slower development of regulatory PFC systems result in increased sensitivity to reward seeking and risky behavior. As such, children and adolescents would be expected to show greater difficulty in coping with distracting emotional information during goal-directed behavior than adults. Mounting research has examined the development of cognitive control (Casey et al., 1995; Bunge et al., 2002; Crone et al., 2006; Rubia et al., 2007; Ernst and Mueller, 2008) and emotion regulation (Herba et al., 2006). The next section will review two sets of studies: (1) studies of cognition emotion interactions in healthy development and (2) cognitive control (and their interaction with emotion) in pediatric mood and anxiety disorders (Table 3).

\section{COGNITION EMOTION INTERACTIONS IN HEALTHY DEVELOPMENT}

A recent, large behavioral study examined the influence of emotional valence on cognitive control in children ages 4-11 and adults, who completed two simple variants of a conflict task (Lagattuta et al., 2011). In the day-night variant, participants responded with the opposite term of an image they were presented with (e.g., respond with "day" to an image showing the night sky). In the happy-sad variant, again, participants were required to respond with the opposite expression. As expected, performance improved linearly with age but performance in the happy-sad task was worse across all groups than the day-night task. In another developmental study, Tottenham et al. (2011) compared performance on an emotional go/no-go task among children (5-12 years), adolescents (13-18 years), and adults (19-28 years). Using a block design, inhibitory control performance was assessed when emotional faces served as the prepotent "go" or the nonprepotent "no-go" stimuli. In-line with prior research, cognitive control, and emotional regulation improved with age. Importantly, across age, false alarms were higher during emotional no-go stimuli relative to neutral no-go stimuli suggesting reduced inhibitory control in the presence of salient emotional information. Additional effects of sex indicated better discrimination of emotion in girls relative to boys. An fMRI variant of the same task that 


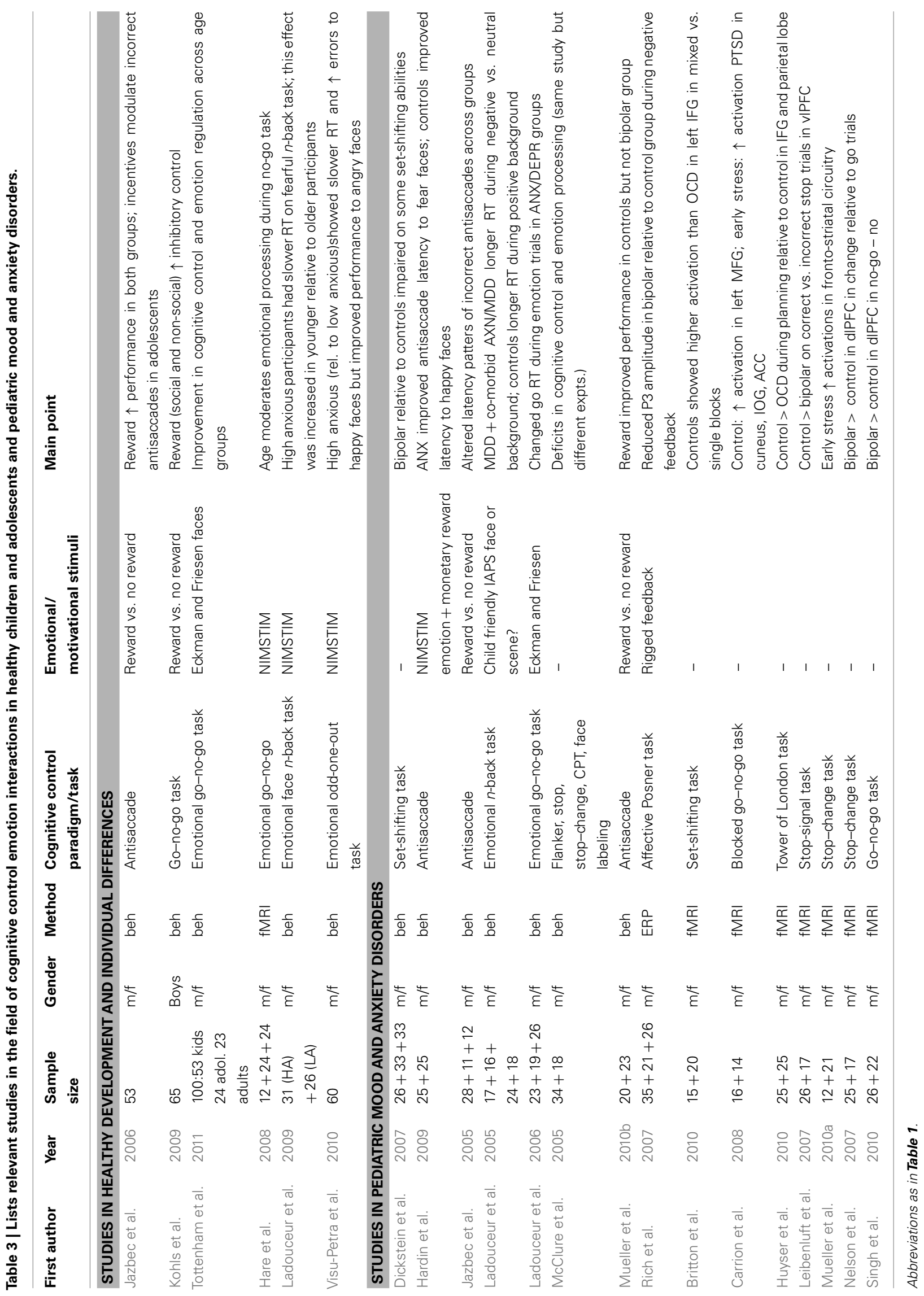


aimed to capture the neural correlates of these effects, increased RT to fearful faces was coupled with higher amygdala activation, while an inverse relationship existed in the ventral PFC (Hare et al., 2008). Moreover, amygdala activation was increased in adolescents relative to children and adults. Taken together, these data imply that basic emotional interference as compared to non-emotional conflict is evident as early as 4 years of age and that emotional neurocircuitry during such conflict tasks is sensitive to development.

Similarly, mirroring parallel research in adults (e.g., Beck et al., 2010; Padmala and Pessoa, 2010; Savine and Braver, 2010), studies of adolescent development have also investigated the impact (Jazbec et al., 2006) and type (Kohls et al., 2009) of motivation on performance. Jazbec et al. (2006) paired antisaccade eye movements with positive (win $\$ 1$ for a correctly executed antisaccade) or negative (lose $\$ 0.5$ for an erroneous antisaccade) reward/punishment contingencies. Although monetary incentive improved inhibitory control during antisaccades in both adolescents and adults, this effect was stronger for the adolescent group. Kohls et al. (2009) used both monetary incentive and social (i.e., positive faces) feedback and documented a stronger improvement of inhibitory control during a go/no-go task in the monetary reward condition in 10-year-old children. These data would advocate that despite the importance of positive caregiver feedback during development, children already show preponderance to secondary reinforcers such as monetary reward.

\section{COGNITION EMOTION INTERACTIONS IN CHILDHOOD MOOD AND ANXIETY DISORDERS}

The previous set of studies informed on the influence of emotion on cognitive control in typically developing individuals. However, neuroanatomical work has implicated disturbances in developmental trajectories of brain circuitry in childhood psychiatric disorders (Shaw et al., 2010). Studies in youths suffering from psychopathology provide a window into the (long-term) developmental changes that mood perturbations may exert on cognitive control. Research in this particular area has utilized several tasks including the (emotional) go/no-go task, the Tower of London task, the flanker task, set-shifting tasks, $n$-back tasks, and the antisaccade task (Table 3).

Antisaccade research in pediatric anxiety has revealed emotiondependent responding whilst executing strong inhibitory control (Hardin et al., 2009). In that study, adolescents with and without an anxiety disorder had to fixate on a centrally presented image of an emotional facial expression (happy, fearful, or neutral). After a short delay, a peripheral asterisk appeared and participants were required to perform an antisaccade to the opposite direction to the asterisk. During instruction prior to the task, participants were told that the face and its emotion were irrelevant and should be ignored. In anxious adolescents, antisaccade latency improved when subjects had to saccade away, i.e., disengage from fearful faces (relative to neutral expressions). By contrast, for controls, antisaccade latency was speeded during the presentation of happy faces relative to neutral faces. Although the principle behind such a study design is reminiscent of tasks investigating attentional biases (e.g., Bar-Haim et al., 2007), the antisaccade task necessitates the execution of strong inhibitory control, which is absent from traditional attentional bias designs. Secondly, although Hardin et al.
(2009) presented face stimuli centrally, it is also possible to present these images peripherally allowing a comparison between engagement and disengagement of emotional stimuli during inhibitory control. Using a similar principle in a study with manual responses, Ladouceur et al. (2005) presented emotional stimuli as background images during performance of a non-emotional $n$-back task in anxious and depressed youths. Interestingly, her findings were the opposite to those of Hardin et al. (2009). Here, Ladouceur et al. (2005) documented prolonged RTs for the depressed group (with and without co-morbid anxiety) in the presence of a negative background (relative to neutral), while controls responded slower during the presentation of a positive background. Due to the differences in methodologies (eye tracking vs. behavioral), tasks (antisaccade vs. $n$-back), groups (depressed vs. anxious), and stimuli (whole scenes vs. faces) it is difficult to isolate the factors that might have contributed to the shift in response patterns. However, regardless of the directionality of the effects, these data indicate that cognitive control, specifically during incidental emotional processing, is altered in pediatric anxiety and depression mirroring patterns in adults.

Adolescents suffering from BD also evidence deficits in cognitive control abilities (McClure et al., 2005; Pavuluri et al., 2006). For instance, on the same group of subjects, McClure et al. (2005) examined both cognitive control abilities and emotional processing in bipolar youth using a variety of executive function measures and face labeling tasks. Although she noted impairments in BD youths in both domains, an interesting avenue would have been to employ tasks testing the potential interaction of these deficits. Preliminary evidence from the antisaccade task suggests that BD youths are insensitive to monetary reward, as antisaccade performance improved with incentive in controls but not patients in another study (Mueller et al., 2010b). Although emotional instability is a hallmark of $\mathrm{BD}$, electrophysiological evidence suggests changes in executive attentional processing in $\mathrm{BD}$ youths during controlled, elicited frustration (Rich et al., 2007) consistent with increased BOLD activity in dlPFPC during inhibitory control tasks (Nelson et al., 2005; Singh et al., 2010). Targeted studies are needed to directly address the influence of emotion on cognitive control processes in pediatric BD.

Studies in pediatric anxiety come to similar conclusions. While much work has focused on establishing the neural correlates of aberrant emotional processing in pediatric anxiety (McClure et al., 2007; Monk et al., 2008), some functional imaging work has investigated cognitive control in types of anxiety disorder such as Obsessive-Compulsive Disorder (Britton et al., 2010; Huyser et al., 2010) or Post-Traumatic Stress Disorder (Carrion et al., 2008). Britton et al. (2010) asked participants with pediatric OCD to complete a simple set-shifting task while undergoing fMRI. Activations for control subjects were increased relative to patients in the left IFG during shift blocks relative to single blocks. Moreover, correlations of behavioral performance with striatal activation were opposite for both groups indicating a drastic change in cognitive control function in OCD. Consistent with Britton et al.'s (2010) findings, Huyser et al. (2010) tested planning abilities in pediatric OCD by virtue of the Tower of London task. Here, activations for controls were also larger relative to patients in left IFG. Of note, while group activations for patients tended to be reduced in the 
OCD studies, they were increased in the bipolar studies. Such data suggests psychopathologic specificity on neural circuitry subserving cognitive control and warrant further enquiry with regards to the emotional phenotype.

Studies in populations at-risk for developing psychopathology provide an intermediate step between healthy development and pediatric mental illness. In two independent but complementary fMRI studies modulation of dACC and PFC activation have been linked to adverse life experiences in cognitive control tasks in these cohorts. Carrion et al. (2008) examined the neural correlates of inhibitory control in youths with post-traumatic stress symptoms due to prior exposure to violence, physical, or sexual abuse. Mueller et al. (2010a) examined cognitive flexibility in international adoptees who had been removed from their biological parents due to emotional neglect. Both studies reported increased activations for the trauma groups relative to age-matched controls in lateral PFC and dACC (BA 32/24). These data suggest that early traumatic experience moderates brain regions involved in cognition emotion interactions. Epidemiological studies suggest that individuals with experience of early trauma are at high risk for developing psychopathology and affective disorders (Green et al., 2010). One question is whether these neurobiological changes in the frontal network may contribute to this increased risk.

\section{SUMMARY AND NEUROCHEMICAL IMPLICATIONS}

Several intriguing findings emerged from this review. Among the most consistent results was that at a behavioral level, negative emotion/stimuli impaired executive control processes while (monetary) reward improved cognitive control function in most cases. The impact of positive emotion on cognitive control was less clear: while some studies found beneficial effects on executive function, this appeared to depend on the exact cognitive process concerned (e.g., perseveration vs. distractibility). At the electrophysiological level, ERP studies had been conducted using within-subject or between-subject designs testing individual differences. These studies have shown that emotional stimuli or anxious state moderated ERP components indicative of executive processes such as the N2, P3, or ERN during error monitoring, conflict resolution, or inhibitory control. In the neurocognitive data, consistent findings emerged with regards to the neural circuitry involved in such integration processes. For example, the dorsolateral PFC, particularly the IFG was generally reactive to emotional (negative) stimuli in the context of a cognitive control process. The middle and frontal gyri of the PFC were also frequently activated during emotional distraction. Given the involvement of the ACC in both executive control and emotion, this structure also turned out to be (unsurprisingly) a major player in interactions between the emotional and executive system. However, consistent findings were not limited to lateral cortical structures but also involved deeper subcortical structures like the amygdala during emotional conflict or even pure non-emotional error processing regardless of response modality (e.g., manual or saccadic; Figure 1).

Although much of the reviewed literature focused on identifying the loci of emotion cognitive control interactions, some of the presented evidence utilized connectivity analyses to point toward a sophisticated and complex network of interactions between individual brain regions. Most consistently reported was a coupling between the ventral/rostral ACC and the amygdala during various forms of conflict involving emotion (e.g., Egner et al., 2008; Kanske and Kotz, 2011a). These authors (Egner et al., 2008) proposed that the rACC exerts a top-down influence on the amygdala response and thereby inhibiting emotional distracter processing during conflict resolution. In other studies, ACC activity was related to dlPFC activations (Mohanty et al., 2007) attributing a mediator role between executive and limbic processes to the ACC (Shackman et al., 2011).

Despite these intriguing findings, one critical question is how these neurobiological data in gray matter relate to mechanisms at the neurochemical level. Neurotransmitters such as dopamine have been postulated to carry important functionality in cognitive control (Braver and Cohen, 2000), on the one hand, and positive emotion (Ashby et al., 1999) and reward and motivational behavior (Schulz, 2002), on the other hand. Given widespread distribution of dopamine throughout the PFC, and a hypothesized role in all three processes, it would seem likely that dopamine might critically contribute to, or mediate, emotional influences on cognitive control. In their model of dopaminergic influences on positive emotion, Ashby et al. (1999) hypothesized that dopamine release from the ventral tegmental area to a wide cortical and subcortical network including the PFC, ACC, Nacc, striatum, hippocampus, or the amygdala, modulates dopaminergic baseline levels in these structures thus up (or down) regulating levels of

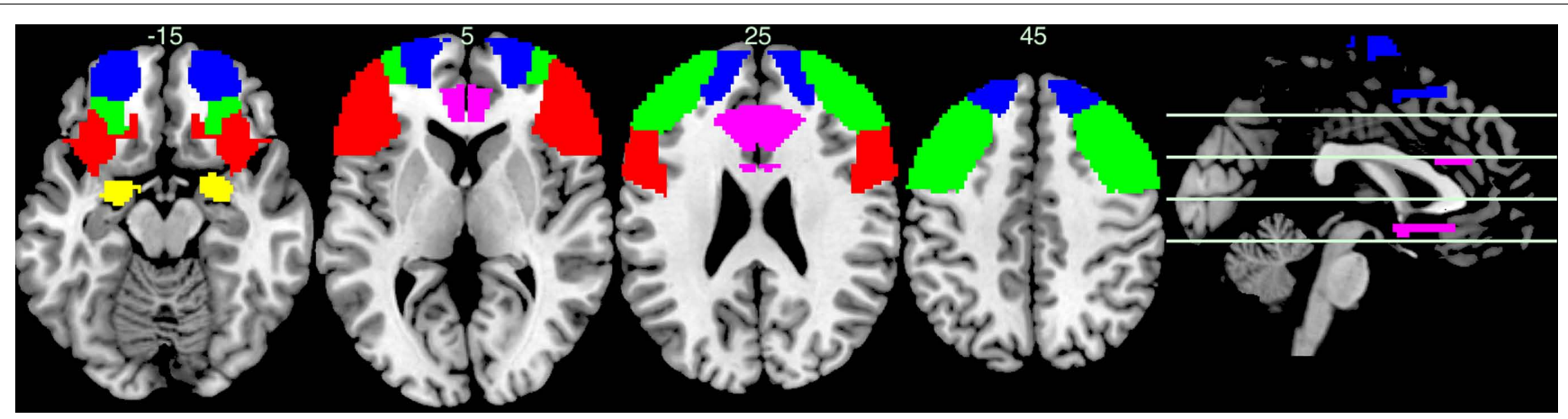

FIGURE 1 | Axial slices of the brain regions consistently reported in studies of cognitive control emotion interactions. Sagittal image on the right shows corresponding height of axial slices. Color schema: Yellow = amygdala, red $=I F G$, green $=M F G$, blue $=S F G$, pink $=A C C$ 
activity and thus influencing affect. According to evidence in favor of this model, a particular crucial role may be played by the Nacc, which enjoys direct connections to the amygdala and PFC and may contribute to evaluating (and updating) goal-directed behavior during error monitoring (Münte et al., 2008). However, as explicitly stated the dopamine theory of positive emotion does not make any predictions about negative emotions or, by extension, valence-specificity of involved brain regions. It could be imagined that the strength of a given region in the evaluation of affective significance relative to the other structures is dependent on the valence of the concerned affective state. Although these details are still under investigation, it appears likely that mesocorticolimbic dopamine pathway is involved in the mediation between emotional and executive processes via subcortical structures. However, it must be pointed out that other neurotransmitters (e.g., serotonin), which also play a pivotal role in emotional behavior, and mood and anxiety disorders in particular (Martinowich et al., 2007), will likely contribute to these neurochemical mechanisms. Therefore, a full account of the neurochemical contribution to emotion cognition interactions should additionally consider other neurotransmitters.

\section{OPEN QUESTIONS FOR FUTURE RESEARCH}

As noted in the previous section, corroborative evidence has emerged on the influence of emotion on cognitive control. Yet, this review has also uncovered some inconsistent findings giving rise to new questions that demand future attention. This section aims to highlight some of these open questions. Since the goal of this review was to reconcile on-going work in adults with emerging research in developmental groups, these questions aim to further research in streams.

A finding that provides a bridge to illustrate the necessity to merge fields is provided by an fMRI study in healthy adults (Schulz et al., 2009) and a DTI study in healthy children (Madsen et al., 2010). In adults, Schulz et al. (2009) reported significant activations during response inhibition to emotional faces in the pars opercularis of the IFG. In the children, Madsen et al. (2010) found that white matter diffusivity (fractional anisotropy, FA) in the pars opercularis predicted behavioral stop-signal reaction time (SSRT). Two conclusions can be drawn. First, these data would suggest that connectivity findings in adolescents may provide clues to explaining some of the variance contributing to performance in functional imaging studies in adults. Second, white matter analyses may contribute to increase our understanding of the neurobiological mechanisms underlying emotion cognition interactions and may complement studies of findings in gray matter.

As noted previously, some theoretical models of emotion propose that both emotion and motivation are necessary to fully account for goal-driven behavior (Roseman, 2008). The reviewed evidence would implicate some shared neurocircuitry such as the PFC (e.g., Van Dillen et al., 2009; Savine and Braver, 2010), while other areas such as the striatum are process-sensitive. While many studies have either investigated reward or emotion separately, one question might concern the level of similarity (or dissimilarity) of effects on cognitive control (see also Chiew and Braver, in this special issue for an outline of such an agenda). Preliminary encouragement for such an endeavor comes from a behavioral study in anxious adolescents that has examined the impact of concurrent reward and incidental emotion processing on antisaccade performance (Hardin et al., 2009). Furthermore, developmental studies have shown that even during young age, secondary reinforcers such as monetary incentive may exert stronger influences than positive (emotional) feedback on executive function (Kohls et al., 2009). Such promising data further strengthen a joint research agenda of adult and developmental work and point toward possible paradigms to examine these issues.

A guaranteed issue for future debate is the extent different emotions (fear, anger, sadness, happiness, disgust) may be processed in diverse neural systems (Habel et al., 2005; Vytal and Hamann, 2010). In other words, to what extent are affective influences on cognitive control emotion-specific? For instance, does one but not another emotion elicit a selective improvement in performance (e.g., Gray, 2001; Lavric et al., 2003)? Does this hold true for the basic emotions such as fear and happiness or does this extend to other emotions such as sadness and disgust?

Although the above questions are of interest to better understand how emotions influence cognitive control, one issue that complicates any positive findings is the generalizability across gender. While some studies have tried to avoid this issue by relying on gender-specific recruitment (Habel et al., 2005; Pereira et al., 2010), initial findings suggest sex-specific neural differences (Koch et al., 2007) supported by developmental work (Tottenham et al., 2011). Such data might suggest that future studies will need to consider any impact of biological sex on their findings regardless of age.

Finally, with regards to clinical relevance and application, the current review has highlighted some exciting developments in adult and pediatric psychopathology in relation to cognitive control dysfunction in mood and anxiety disorders. Following psychological theories that propose executive deficits in depression (Joormann, 2010) or anxiety (Eysenck et al., 2007), a future line of research could examine to what extent therapeutic training on cognitive control measures might improve symptomatology and alter interactions with executive control.

\section{CONCLUSION}

Within the last decade much progress has been made to understand the neurobiological mechanisms underlying emotional influences on executive processes. While clear candidate regions, particularly the PFC, have been identified, open questions concern the relationship between individual regions. An important task for future work will be to integrate theoretical models of emotion and cognitive control and define the conditions under which these systems may recruit additional or distinct neurocircuitry from their respective networks. Despite moderate progress in adults, developmental research in the field is still in its infancy. Delineating the dynamic changes of these interactive processes across time may provide critical information on the psychological and neurobiological mechanisms by which affective processes perturb cognitive control in the developing brain. In turn, such discovery might aid in understanding the ontogenesis of pediatric mood and anxiety disorders during a period of constant change. 


\section{REFERENCES}

Aarts, K., and Pourtois, G. (2010). Anxiety not only increases, but also alters early error-monitoring functions. Cogn. Affect. Behav. Neurosci. 10, 479-492.

Albert, J., Lopez-Martin, S., and Carretie, L. (2010). Emotional context modulates response inhibition: neural and behavioral data. $\mathrm{Neu}$ roimage 49, 914-921.

Amodio, D. M., Master, S. L., Yee, C. M., and Taylor, S. E. (2008). Neurocognitive components of the behavioral inhibition and activation systems: implications for theories of self-regulation. Psychophysiology 45, 11-19.

Ansari, T. L., and Derakshan, N. (2011). The neural correlates of cognitive effort in anxiety: effects on processing efficiency. Biol. Psychol. 86, 337-348.

Ansari, T. L., Derakshan, N., and Richards, A. (2008). Effects of anxiety on task switching: evidence from the mixed antisaccade task. Cogn. Affect. Behav. Neurosci. 8, 229-238.

Arnold, M. B. (1960). Emotion and Personality. New York, NY: Columbia University Press.

Aron, A. R., Durston, S., Eagle, D. M., Logan, G. D., Stinear, C. M., and Stuphorn, V. (2007). Converging evidence for a fronto-basal-ganglia network for inhibitory control of action and cognition. J. Neurosci. 27, 11860-11864.

Ashby, F. G., Isen, A. M., and Turken, A. U. (1999). A neuropsychological theory of positive affect and its influence on cognition. Psychol. Rev. 106, 529-550.

Banich, M. T. (2009). Executive function: the search for an integrated account. Curr. Dir. Psychol. Sci. 18, 89-94.

Banich, M. T., Mackiewicz, K. L., Depue, B. E., Whitmer, A. J., Miller, G. A., and Heller, W. (2009). Cognitive control mechanisms, emotion and memory: a neural perspective with implications for psychopathology. Neurosci. Biobehav. Rev. 33, 613-630.

Bar-Haim, Y., Lamy, D., Pergamin, L., Bakermans-Kranenburg, M. J., and van IJzendoorn, M. H. (2007). Threat-related attentional bias in anxious and nonanxious individuals: a meta-analytic study. Psychol. Bull. 133, 1-24.

Barnes, J. J., Dean, A. J., Nandam, L. S., O'Connell, R. G., and Bellgrove, M. A. (2011). The molecular genetics of executive function: role of monoamine system genes. Biol. Psychiatry 69, e127-e143.

Beck, S. M., Locke, H. S., Savine, A. C., Jimura, K., and Braver, T. S. (2010).
Primary and secondary rewards differentially modulate neural activity dynamics during working memory. PLoS ONE 5, e9251. doi:10.1371/journal.pone.0009251

Bermudez, M. A., and Schultz, W. (2010). Reward magnitude coding in primate amygdala neurons. J. Neurophysiol. 104, 3424-3432.

Bishop, S. J. (2009). Trait anxiety and impoverished prefrontal control of attention. Nat. Neurosci. 12, 92-98.

Bishop, S. J., Cohen, J. D., Fossella, J., Casey, B. J., and Farah, M. J. (2006). COMT genotype influences prefrontal response to emotional distraction. Cogn. Affect. Behav. Neurosci. 6, 62-70.

Bishop, S. J., Duncan, J., Brett, M., and Lawrence, A. D. (2004). Prefrontal cortical function and anxiety: controlling attention to threat-related stimuli. Nat. Neurosci. 7, 184-188.

Blair, K. S., Smith, B. W., Mitchell, D. G. Morton, J., Vythilingam, M., Pessoa, L., Fridberg, D., Zametkin, A., Sturman, D., Nelson, E. E., Drevets, W. C., Pine, D. S., Martin, A., and Blair, R. J. (2007). Modulation of emotion by cognition and cognition by emotion. Neuroimage 35, 430-440.

Boehler, C. N., Bunzeck, N., Krebs, R. M., Noesselt, T., Schoenfeld, M. A., Heinze, H. J., Münte, T. F., Woldorff, M. G., and Hopf, J. M. (2011a). Substantia nigra activity level predicts trial-to-trial adjustments in cognitive control. J. Cogn. Neurosci. 23, 362-373.

Boehler, C. N., Hopf, J. M., Krebs, R. M., Stoppel, C. M., Schoenfeld, M. A., Heinze, H. J., and Noesselt, T. (2011b). Task-load-dependent activation of dopaminergic midbrain areas in the absence of reward. J. Neurosci. 31, 4955-4961.

Botvinick, M., Nystrom, L. E., Fissell, K., Carter, C. S., and Cohen, J. D. (1999). Conflict monitoring versus selection-for-action in anterior cingulate cortex. Nature 402, 179-181.

Bradley, M. M., and Lang, P. J. (1999). Affective Norms for English Words (ANEW): Instruction Manual and Affective Ratings. Technical Report C-1, the Center for Research in Psychophysiology. University of Florida, Gainesville.

Brass, M., and von Cramon, Y. D. (2002). The role of the frontal cortex in task preparation. Cereb. Cortex 12, 908-914.

Braver, T. S., and Cohen, J. D. (2000). "On the control of control: the role of dopamine regulating prefrontal function and working memory," in Attention and Performance XVIII, eds S. Monsell and J. Driver (Cambridge, MA: MIT Press), 713-737.
Britton, J. C., Rauch, S. L., Rosso, I. M., Killgore, W. D., Price, L. M., Ragan, J., Chosak, A., Hezel, D. M., Pine, D. S., Leibenluft, E., Pauls, D. L., Jenike, M. A., and Stewart, S. E. (2010). Cognitive inflexibility and frontal-cortical activation in pediatric obsessive-compulsive disorder. J. Am. Acad. Child Adolesc. Psychiatry 49, 944-953.

Brosch, T., Sander, D., Pourtois, G., and Scherer, K. R. (2008). Beyond fear: rapid spatial orienting toward positive emotional stimuli. Psychol. Sci. 19, 362-370.

Buhle, J., and Wager, T. D. (2010). Performance-dependent inhibition of pain by an executive working memory task. Pain 149, 19-26.

Bunge, S. A., Dudukovic, N. M., Thomason, M. E., Vaidya, C. J., and Gabrieli, J. D. (2002). Immature frontal lobe contributions to cognitive control in children: evidence from fMRI. Neuron 33, 301-311.

Bush, G., Luu, P., and Posner, M. I. (2000). Cognitive and emotional influences in anterior cingulate cortex. Trends Cogn. Sci. (Regul. Ed.) 4 , 215-222.

Carrion, V. G., Garrett, A., Menon, V., Weems, C. F., and Reiss, A. L. (2008). Posttraumatic stress symptoms and brain function during a response-inhibition task: an fMRI study in youth. Depress. Anxiety 25, 514-526.

Casey, B. J., Cohen, J. D., Jezzard, P., Turner, R., Noll, D. C., Trainor, R. J., Giedd, J., Kaysen, D., Hertz-Pannier, L., and Rapoport, J. L. (1995). Activation of prefrontal cortex in children during a nonspatial working memory task with functional MRI. Neuroimage 2, 221-229.

Compton, R. J., Banich, M. T., Mohanty, A., Milham, M. P., Herrington, J., Miller, G. A., Scalf, P. E., Webb, A., and Heller, W. (2003). Paying attention to emotion: an fMRI investigation of cognitive and emotional Stroop tasks. Cogn. Affect. Behav. Neurosci. 3, 81-96.

Crone, E. A., Wendelken, C., Donohue, S., van Leijenhorst, L., and Bunge, S. A. (2006). Neurocognitive development of the ability to manipulate information in working memory. Proc. Natl. Acad. Sci. U.S.A. 103 9315-9320.

Dahl, R. E. (2004). Adolescent brain development: a period of vulnerabilities and opportunities. Ann. N. Y. Acad. Sci. 1021, 1-22.

Dalgleish, T. (2004). The emotional brain. Nat. Rev. Neurosci. 5, 583-589.

Damasio, A. R. (1996). The somatic marker hypothesis and the possible functions of the prefrontal cortex.
Philos. Trans. R. Soc. Lond. B Biol. Sci. 351, 1413-1420.

Davidson, R. J. (1995). "Cerebral asymmetry, emotion, and affective style," in Brain Asymmetry, eds R. J. Davidson and K. Hughdahl (Cambridge, MA: MIT Press), 361-387.

Davis, R. N., and Nolen-Hoeksema, S. (2000). Cognitive inflexibility among ruminators and nonruminators. Cognit. Ther. Res. 24, 699-711.

De Houwer, J., and Tibboel, H. (2010). Stop what you are not doing! Emotional pictures interfere with the task not to respond. Psychon. Bull. Rev. 17, 699-703.

De Lissnyder, E., Koster, E., Derakshan, N., and De Raedt, R. (2010). The association between depressive symptoms and executive control impairments in response to emotional and non-emotional information. Cogn. Emot. 24, 264-280.

Denkova, E., Wong, G., Dolcos, S., Sung, K., Wang, L., Coupland, N., and Dolcos, F. (2010). The impact of anxiety-inducing distraction on cognitive performance: a combined brain imaging and personality investigation. PLoS ONE 5, e14150. doi:10.1371/journal.pone.0014150

Derakshan, N., Ansari, T. L., Hansard, M., Shoker, L., and Eysenck, M. W. (2009a). Anxiety, inhibition, efficiency, and effectiveness. An investigation using antisaccade task. Exp. Psychol. 56, 48-55.

Derakshan, N., Smyth, S., and Eysenck, M. W. (2009b). Effects of state anxiety on performance using a taskswitching paradigm: an investigation of attentional control theory. Psychon. Bull. Rev. 16, 1112-1117.

Dickstein, D. P., Nelson, E. E., McClure, E. B., Grimley, M. E., Knopf, L., Brotman, M. A., Rich, B. A., Pine, D. S., and Leibenluft, E. (2007). Cognitive flexibility in phenotypes of pediatric bipolar disorder. J. Am. Acad. Child Adolesc. Psychiatry 46, 341-355.

Dolcos, F., Diaz-Granados, P., Wang, L., and McCarthy, G. (2008). Opposing influences of emotional and non-emotional distracters upon sustained prefrontal cortex activity during a delayed-response working memory task. Neuropsychologia 46 , 326-335.

Dolcos, F., Kragel, P., Wang, L., and McCarthy, G. (2006). Role of the inferior frontal cortex in coping with distracting emotions. Neuroreport 17, 1591-1594.

Dolcos, F., and McCarthy, G. (2006). Brain systems mediating cognitive interference by emotional distraction. J. Neurosci. 26, 2072-2079. 
Dreher, J. C., Koechlin, E., Ali, S. O., and Grafman, J. (2002). The roles of timing and task order during task switching. Neuroimage 17, 95-109.

Dreisbach, G., and Goschke, T. (2004). How positive affect modulates cognitive control: reduced perseveration at the cost of increased distractibility. J. Exp. Psychol. Learn. Mem. Cogn. 30, 343-353.

Duncan, J., and Owen, A. M. (2000). Common regions of the human frontal lobe recruited by diverse cognitive demands. Trends Neurosci. 23, 475-483.

Egner, T., Etkin, A., Gale, S., and Hirsch, J. (2008). Dissociable neural systems resolve conflict from emotional versus nonemotional distracters. Cereb. Cortex 18, 1475-1484.

Ekman, P., and Friesen, W. V. (1976). Pictures of Facial Affect. Palo Alto, CA: Consulting Psychologists Press.

Elliott, R., Ogilvie, A., Rubinsztein, J. S., Calderon, G., Dolan, R. J., and Sahakian, B. J. (2004). Abnormal ventral frontal response during performance of an affective go/no go task in patients with mania. Biol. Psychiatry 55, 1163-1170.

Engels, A. S., Heller, W., Mohanty, A., Herrington, J. D., Banich, M. T., Webb, A. G., and Miller, G. A. (2007). Specificity of regional brain activity in anxiety types during emotion processing. Psychophysiology 44, 352-363.

Ernst, M., and Mueller, S. C. (2008). The adolescent brain: insights from functional neuroimaging research. Dev. Neurobiol. 68, 729-743.

Ernst, M., Pine, D. S., and Hardin, M. (2006). Triadic model of the neurobiology of motivated behavior in adolescence. Psychol. Med. 36, 299-312.

Erthal, F. S., de Oliveira, L., Mocaiber, I., Pereira, M. G., Machado-Pinheiro, W., Volchan, E., and Pessoa, L. (2005). Load-dependent modulation of affective picture processing. Cogn. Affect. Behav. Neurosci. 5, 388-395.

Etkin, A., Egner, T., Peraza, D. M., Kandel, E. R., and Hirsch, J. (2006). Resolving emotional conflict: a role for the rostral anterior cingulate cortex in modulating activity in the amygdala. Neuron 51, 871-882.

Eysenck, M. W., Derakshan, N., Santos, R., and Calvo, M. G. (2007). Anxiety and cognitive performance: attentional control theory. Emotion 7, 336-353.

Fales, C. L., Barch, D. M., Burgess, G. C., Schaefer, A., Mennin, D. S., Gray, J. R., and Braver, T. S. (2008). Anxiety and cognitive efficiency: differential modulation of transient and sustained neural activity during a working memory task. Cogn. Affect. Behav. Neurosci. 8, 239-253.

Fales, C. L., Becerril, K. E., Luking, K. R., and Barcha, D. M. (2010). Emotional-stimulus processing in trait anxiety is modulated by stimulus valence during neuroimaging of a working memory task. Cogn. Emot. 24, 200-222.

Falkenstein, M., Hohnsbein, J., Hoormann, J., and Blanke, L. (1990). "Effects of errors in choice reaction task on the ERP under focused and divided attention," in Psychophysiological Brain Research, eds C. H. M. Brunia, A. W. K. Gaillard, and A. Kok (Tilburg: Tilburg University Press), 192-195.

Frijda, N. H. (1988). The Laws of Emotion. Mahwah, NJ: Lawrence Erlbaum Associates.

Fuster, J. (1997). The Prefrontal Cortex. New York: Lippincott-Raven.

Gehring, W. J., Goss, B., Coles, M. G. H., Meyer, D. E., and Donchin, E. (1993). A neural system for error-detection and compensation. Psychol. Sci. 4, 385-390.

Giedd, J. N., Blumenthal, J., Jeffries, N. O., Castellanos, F. X., Liu, H., Zijdenbos, A., Paus, T., Evans, A. C., and Rapoport, J. L. (1999). Brain development during childhood and adolescence: a longitudinal MRI study [2]. Nat. Neurosci. 2, 861-863.

Gogtay, N., Giedd, J. N., Lusk, L., Hayashi, K. M., Greenstein, D., Vaituzis, A. C., Nugent, T. F. III, Herman, D. H., Clasen, L. S., Toga, A. W., Rapoport, J. L., and Thompson, P. M. (2004). Dynamic mapping of human cortical development during childhood through early adulthood. Proc. Natl. Acad. Sci. U.S.A. 101, 8174-8179.

Goldman-Rakic, P. S. (1995). "Architecture of the prefrontal cortex and the central executive," in Structures and Functions of the Human Prefrontal Cortex, eds J. Grafman, K. J. Holyoak, and F. Boller (New York, NY: Academy of Sciences), 71-83.

Goldstein, M., Brendel, G., Tuescher, O., Pan, H., Epstein, J., Beutel, M., Yang, Y., Thomas, K., Levy, K., Silverman, M., Clarkin, J., Posner, M., Kernberg, O., Stern, E., and Silbersweig, D. (2007). Neural substrates of the interaction of emotional stimulus processing and motor inhibitory control: an emotional linguistic go/no-go fMRI study. Neuroimage 36, 1026-1040.

Gray, J., and McNaughton, N. (2000). The Neuropsychology of Anxiety. Oxford: Oxford University Press.
Gray, J. R. (2001). Emotional modulation of cognitive control: approachwithdrawal states double-dissociate spatial from verbal two-back task performance. J. Exp. Psychol. Gen. 130, 436-452.

Gray, J. R., and Braver, T. S. (2002). Personality predicts working-memoryrelated activation in the caudal anterior cingulate cortex. Cogn. Affect. Behav. Neurosci. 2, 64-75.

Gray, J. R., Braver, T. S., and Raichle, M. E. (2002). Integration of emotion and cognition in the lateral prefrontal cortex. Proc. Natl. Acad. Sci. U.S.A. 99, 4115-4120.

Gray, J. R., Burgess, G. C., Schaefer, A., Yarkoni, T., Larsen, R. J., and Braver, T. S. (2005). Affective personality differences in neural processing efficiency confirmed using fMRI. Cogn. Affect. Behav. Neurosci. 5, 182-190.

Green, J. G., McLaughlin, K. A. Berglund, P. A., Gruber, M. J., Sampson, N. A., Zaslavsky, A. M., and Kessler, R. C. (2010). Childhood adversities and adult psychiatric disorders in the national comorbidity survey replication I: associations with first onset of DSM-IV disorders. Arch. Gen. Psychiatry 67, 113-123.

Gur, R. C., Sara, R., Hagendoorn, M., Marom, O., Hughett, P., Macy, L., Turner, T., Bajcsy, R., Posner, A., and Gur, R. E. (2002). A method for obtaining 3-dimensional facial expressions and its standardization for use in neurocognitive studies. J. Neurosci. Methods 115, 137-143.

Habel, U., Klein, M., Kellermann, T. Shah, N. J., and Schneider, F. (2005). Same or different? Neural correlates of happy and sad mood in healthy males. Neuroimage 26, 206-214.

Hajcak, G., and Foti, D. (2008). Errors are aversive: defensive motivation and the error-related negativity. Psychol. Sci. 19, 103-108.

Hardin, M. G., Mandell, D., Mueller, S. C., Dahl, R. E., Pine, D. S., and Ernst, M. (2009). Inhibitory control in anxious and healthy adolescents is modulated by incentive and incidental affective stimuli. J. Child Psychol. Psychiatry 50, 1550-1558.

Hare, T. A., Tottenham, N., Davidson, M. C., Glover, G. H., and Casey, B. J. (2005). Contributions of amygdala and striatal activity in emotion regulation. Biol. Psychiatry 57, 624-632.

Hare, T. A., Tottenham, N., Galvan, A. Voss, H. U., Glover, G. H., and Casey, B. J. (2008). Biological substrates of emotional reactivity and regulation in adolescence during an emotional go-nogo task. Biol. Psychiatry 63 927-934.
Harvey, P. O., Fossati, P., Pochon, J. B., Levy, R., Lebastard, G., Lehéricy, S., Allilaire, J. F., and Dubois, B. (2005). Cognitive control and brain resources in major depression: an fMRI study using the n-back task. Neuroimage 26, 860-869.

Herba, C. M., Landau, S., Russell, T., Ecker, C., and Phillips, M. L. (2006). The development of emotion-processing in children: effects of age, emotion, and intensity. J. Child Psychol. Psychiatry 47, 1098-1106.

Herrington, J. D., Heller, W., Mohanty, A., Engels, A. S., Banich, M. T., Webb A. G., and Miller, G. A. (2010). Localization of asymmetric brain function in emotion and depression. Psychophysiology 47, 442-454.

Herrington, J. D., Mohanty, A., Koven, N. S., Fisher, J. E., Stewart, J. L. Banich, M. T., Webb, A. G., Miller, G. A., and Heller, W. (2005). Emotionmodulated performance and activity in left dorsolateral prefrontal cortex. Emotion 5, 200-207.

Holmes, A. J., and Pizzagalli, D. A. (2007). Task feedback effects on conflict monitoring and executive control: relationship to subclinical measures of depression. Emotion 7, 68-76.

Huyser, C., Veltman, D. J., Wolters, L. H., de Haan, E., and Boer, F. (2010). Functional magnetic resonance imaging during planning before and after cognitivebehavioral therapy in pediatric obsessive-compulsive disorder. J. Am. Acad. Child Adolesc. Psychiatry 49, 1238-1248; e1231-e1235.

James, W. (1884). What is an emotion. Mind 9, 188-205.

Jazbec, S., Hardin, M. G., Schroth, E., McClure, E., Pine, D. S., and Ernst, M. (2006). Age-related influence of contingencies on a saccade task. Exp. Brain Res. 174, 754-762.

Jazbec, S., McClure, E., Hardin, M., Pine, D. S., and Ernst, M. (2005). Cognitive control under contingencies in anxious and depressed adolescents: an antisaccade task. Biol. Psychiatry $58,632-639$.

Joormann, J. (2010). Cognitive inhibition and emotion regulation in depression. Curr. Dir. Psychol. Sci. 19, 161-166.

Joormann, J., and Gotlib, I. H. (2008). Updating the contents of working memory in depression: interference from irrelevant negative material. $J$. Abnorm. Psychol. 117, 182-192.

Kanske, P., and Kotz, S. A. (2010a). Modulation of early conflict processing: N200 responses to emotional words in a flanker task. Neuropsychologia 48, 3661-3664. 
Kanske, P., and Kotz, S. A. (2010b). Leipzig affective norms for German: a reliability study. Behav. Res. Methods 42, 987-991.

Kanske, P., and Kotz, S. A. (2011a). Emotion triggers executive attention: anterior cingulate cortex and amygdala responses to emotional words in a conflict task. Hum. Brain Mapp. 32, 198-208.

Kanske, P., and Kotz, S. A. (2011b). Emotion speeds up conflict resolution: a new role for the ventral anterior cingulate cortex? Cereb. Cortex 21, 911-919.

Kensinger, E. A., and Corkin, S. (2003). Effect of negative emotional content on working memory and long-term memory. Emotion 3, 378-393.

Kobayashi, S., Pinto de Carvalho, O., and Schultz, W. (2010). Adaptation of reward sensitivity in orbitofrontal neurons. J. Neurosci. 30, 534-544.

Koch, K., Pauly, K., Kellermann, T., Seiferth, N. Y., Reske, M., Backes, V., Stöcker, T., Shah, N. J., Amunts, K., Kircher, T., Schneider, F., and Habel, U. (2007). Gender differences in the cognitive control of emotion: an fMRI study. Neuropsychologia 45, 2744-2754.

Koechlin, E., Basso, G., Pietrini, P., Panzer, S., and Grafman, J. (1999). The role of the anterior prefrontal cortex in human cognition. Nature 399, 148-151.

Koechlin, E., Corrado, G., Pietrini, P., and Grafman, J. (2000). Dissociating the role of the medial and lateral anterior prefrontal cortex in human planning. Proc. Natl. Acad. Sci. U.S.A. 97, 7651-7656.

Koechlin, E., Ody, C., and Kouneiher, F. (2003). The architecture of cognitive control in the human prefrontal cortex. Science 302, 1181-1185.

Kohls, G., Peltzer, J., HerpertzDahlmann, B., and Konrad, K. (2009). Differential effects of social and non-social reward on response inhibition in children and adolescents. Dev. Sci. 12, 614-625.

Koven, N. S., Heller, W., Banich, M. T., and Miller, G. A. (2003). Relationships of distinct affective dimensions to performance on an emotional Stroop task. Cognit. Ther. Res. 27, 671-680.

Krebs, R. M., Boehler, C. N., Egner, T., and Woldorff, M. G. (2011). Associations can both guide and misguide attention. J. Neurosci. 31, 9752-9759.

Krebs, R. M., Boehler, C. N., Roberts, K. C., Song, A. W., and Woldorff, M. G. (in press). The involvement of the dopaminergic midbrain and cortico-striatal-thalamic circuits in the integration of reward prospect and attentional task demands. Cereb. Cortex. doi: 10.1093/cercor/bhr134. [Epub ahead of print].

Krebs, R. M., Boehler, C. N., and Woldorff, M. G. (2010). The influence of reward associations on conflict processing in the Stroop task. Cognition 117, 341-347.

Ladouceur, C. D., Dahl, R. E., Williamson, D. E., Birmaher, B., Axelson, D. A., Ryan, N. D., and Casey, B. J. (2006). Processing emotional facial expressions influences performance on a go/nogo task in pediatric anxiety and depression. J. Child. Psychol. Psychiatry 47, 1107-1115.

Ladouceur, C. D., Dahl, R. E., Williamson, D. E., Birmaher, B., Ryan, N. D., and Casey, B. J. (2005). Altered emotional processing in pediatric anxiety, depression, and comorbid anxiety-depression. J. Abnorm. Child. Psychol. 33, 165-177.

Ladouceur, C. D., Silk, J. S., Dahl, R. E., Ostapenko, L., Kronhaus, D. M., and Phillips, M. L. (2009). Fearful faces influence attentional control processes in anxious youth and adults. Emotion 9, 855-864.

Lagattuta, K. H., Sayfan, L., and Monsour, M. (2011). A new measure for assessing executive function across a wide age range: children and adults find happy-sad more difficult than day-night. Dev. Sci. 14, 481-489.

Lang, P. J., Bradley, M. M., and Cuthbert, B. N. (1990). Emotion, attention, and the startle reflex. Psychol. Rev. 97, 377-395.

Lang, P. J., Bradley, M. M., and Cuthbert, B. N. (2008). International Affective Picture System (IAPS): Affective Ratings of Pictures and Instruction Manual. Technical Report A8. Gainesville, FL: University of Florida.

Lange, C. (1885). "The emotions," in The Emotions, ed. E. Dunlap (Baltimore, MD: Williams \& Wilkins), 33-90.

Lavric, A., Rippon, G., and Gray, J. R. (2003). Threat-evoked anxiety disrupts spatial working memory performance: an attentional account. Cognit. Ther. Res. 27, 489-504.

Lazarus, R. S. (1991). Emotion and Adaptation. New York, NY: Oxford University Press.

LeDoux, J. E. (2000). Emotion circuits in the brain. Annu. Rev. Neurosci. 23, 155-184.

Legrain, V., Crombez, G., Verhoeven, K., and Mouraux, A. (2011). The role of working memory in the attentional control of pain. Pain 152, 453-459.

Leibenluft, E., Rich, B. A., Vinton, D. T., Nelson, E. E., Fromm, S. J.,
Berghorst, L. H., Joshi, P., Robb, A., Schachar, R. J., Dickstein, D. P., McClure, E. B., and Pine, D. S. (2007). Neural circuitry engaged during unsuccessful motor inhibition in pediatric bipolar disorder. Am. J. Psychiatry 164, 52-60.

Levens, S. M., and Gotlib, I. H. (2010). Updating positive and negative stimuli in working memory in depression. J. Exp. Psychol. Gen. 139, 654-664.

Levens, S. M., and Phelps, E. A. (2008), Emotion processing effects on interference resolution in working memory. Emotion 8, 267-280.

Levens, S. M., and Phelps, E. A (2010). Insula and orbital frontal cortex activity underlying emotion interference resolution in working memory. J. Cogn. Neurosci. 22 2790-2803.

Leyman, L., De Raedt, R., Vanderhasselt, M. A., and Baeken, C. (2009). Influence of high-frequency repetitive transcranial magnetic stimulation over the dorsolateral prefrontal cortex on the inhibition of emotional information in healthy volunteers. Psychol. Med. 39, 1019-1028.

Li, C. S., Chao, H. H., and Lee, T. W. (2009). Neural correlates of speeded as compared with delayed responses in a stop signal task: an indirect ana$\log$ of risk taking and association with an anxiety trait. Cereb. Cortex 19, 839-848.

Liao, W., Chen, H., Feng, Y., Mantini, D., Gentili, C., Pan, Z., Ding, J., Duan, X., Qiu, C., Lui, S., Gong, Q., and Zhang, W. (2010). Selective aberrant functional connectivity of resting state networks in social anxiety disorder. Neuroimage 52, 1549-1558.

Lim, S. L., Padmala, S., and Pessoa, L. (2008). Affective learning modulates spatial competition during lowload attentional conditions. Neuropsychologia 46, 1267-1278.

Lundqvist, D., Flykt, A., and Öhman, A. (1998). The Karolinska Riected Emotional Faces - KDEF. CDROM From Department of Clinical Neuroscience, Psychology Section, Karolinska Institutet, Stockholm.

Luu, P., Collins, P., and Tucker, D. M. (2000). Mood, personality, and self-monitoring: negative affect and emotionality in relation to frontal lobe mechanisms of error monitoring. J. Exp. Psychol. 129, 43-60.

Madsen, K. S., Baare, W. F., Vestergaard, M., Skimminge, A., Ejersbo, L. R., Ramsøy, T. Z., Gerlach, C., Akeson, P., Paulson, O. B., and Jernigan, T. L. (2010). Response inhibition is associated with white matter microstructure in children. Neuropsychologia 48, 854-862.

Martinowich, K., Manji, H., and Lu, B. (2007). New insights into BDNF function in depression and anxiety. Nat. Neurosci. 10, 1089-1093.

McClure, E. B., Monk, C. S., Nelson, E. E., Parrish, J. M., Adler, A., Blair, R. J., Fromm, S., Charney, D. S., Leibenluft, E., Ernst, M., and Pine, D. S. (2007). Abnormal attention modulation of fear circuit function in pediatric generalized anxiety disorder. Arch. Gen. Psychiatry 64, 97-106.

McClure, E. B., Treland, J. E., Snow, J., Schmajuk, M., Dickstein, D. P., Towbin, K. E., Charney, D. S., Pine, D. S., and Leibenluft, E. (2005). Deficits in social cognition and response flexibility in pediatric bipolar disorder. Am. J. Psychiatry 162, 1644-1651.

Miller, E. K., and Cohen, J. D. (2001). An integrative theory of prefrontal cortex function. Annu. Rev. Neurosci. 24 167-202.

Mills, C. K. (1912). The cerebral mechanisms of emotional expression. Trans. Coll. Physicians Phila. 34, 381-390.

Miyake, A., Friedman, N. P., Emerson, M. J., Witzki, A. H., Howerter, A., and Wager, T. D. (2000). The unity and diversity of executive functions and their contributions to complex "frontal lobe" tasks: a latent variable analysis. Cogn. Psychol. 41, 49-100.

Mohanty, A., Engels, A. S., Herrington, J. D., Heller, W., Ho, M. H., Banich, M. T., Webb, A. G., Warren, S. L., and Miller, G. A. (2007). Differential engagement of anterior cingulate cortex subdivisions for cognitive and emotional function. Psychophysiology 44, 343-351.

Monk, C. S., Telzer, E. H., Mogg, K., Bradley, B. P., Mai, X., Louro, H. M., Chen, G., McClure-Tone, E. B., Ernst, M., and Pine, D. S. (2008). Amygdala and ventrolateral prefrontal cortex activation to masked angry faces in children and adolescents with generalized anxiety disorder. Arch. Gen. Psychiatry 65, 568-576.

Moratti, S., Keil, A., and Miller, G. A. (2006). Fear but not awareness predicts enhanced sensory processing in fear conditioning. Psychophysiology 43, 216-226.

Mueller, S. C., Maheu, F. S., Dozier M., Peloso, E., Mandell, D., Leibenluft, E., Pine, D. S., and Ernst, M. (2010a). Early-life stress is associated with impairment in cognitive control in adolescence: an fMRI study. Neuropsychologia 48, 3037-3044. 
Mueller, S. C., Ng, P., Temple, V., Hardin, M. G., Pine, D. S., Leibenluft, E., and Ernst, M. (2010b). Perturbed reward processing in pediatric bipolar disorder: an antisaccade study. $J$. Psychopharmacol. 24, 1779-1784.

Münte, T. F., Heldmann, M., Hinrichs, H., Marco-Pallares, J., Krämer, U. M., Sturm, V., and Heinze, H. J. (2008). Nucleus accumbens is involved in human action monitoring: evidence from invasive electrophysiological recordings. Front. Hum. Neurosci. 1:11. doi:10.3389/neuro.09.011.2007

Nelson, E. E., Leibenluft, E., McClure, E. B., and Pine, D. S. (2005). The social re-orientation of adolescence: a neuroscience perspective on the process and its relation to psychopathology. Psychol. Med. 35, 163-174.

Nelson, E. E., Vinton, D. T., Berghorst, L., Towbin, K. E., Hommer, R. E., Dickstein, D. P., Rich, B. A., Brotman, M. A., Pine, D. S., and Leibenluft, E. (2007). Brain systems underlying response flexibility in healthy and bipolar adolescents: an eventrelated fMRI study. Bipolar Disord. 9, 810-819.

Norman, D., and Shallice, T. (1986). "Attention to action: willed and automatic control of behavior," in Consciousness and Self Regulation: Advances in Research and Theory, Vol. 4, eds R. Davidson, G. Schwartz, and D. Shapiro (New York: Plenum), $1-18$.

Ochsner, K. N., and Gross, J. J. (2005). The cognitive control of emotion. Trends Cogn. Sci. (Regul. Ed.) 9, 242-249.

Ousdal, O. T., Jensen, J., Server, A., Hariri, A. R., Nakstad, P. H., and Andreassen, O. A. (2008). The human amygdala is involved in general behavioral relevance detection: evidence from an event-related functional magnetic resonance imaging go-nogo task. Neuroscience 156, 450-455.

Padmala, S., and Pessoa, L. (2010). Interactions between cognition and motivation during response inhibition. Neuropsychologia 48, 558-565.

Panksepp, J. (1998). Affective Neuroscience: The Foundations of Human and Animal Emotions. New York: Oxford University Press.

Paus, T., Zijdenbos, A., Worsley, K., Collins, D. L., Blumenthal, J., Giedd, J. N., Rapoport, J. L., and Evans, A. C. (1999). Structural maturation of neural pathways in children and adolescents: in vivo study. Science 283, 1908-1911.

Pavuluri, M. N., Schenkel, L. S., Aryal, S., Harral, E. M., Hill, S. K.,
Herbener, E. S., and Sweeney, J. A. (2006). Neurocognitive function in unmedicated manic and medicated euthymic pediatric bipolar patients. Am. J. Psychiatry 163, 286-293.

Pereira, M. G., de Oliveira, L., Erthal, F. S., Joffily, M., Mocaiber, I. F., Volchan, E., and Pessoa, L. (2010). Emotion affects action: midcingulate cortex as a pivotal node of interaction between negative emotion and motor signals. Cogn. Affect. Behav. Neurosci. 10, 94-106.

Pereira, M. G., Volchan, E., de Souza, G. G., Oliveira, L., Campagnoli, R. R., Pinheiro, W. M., and Pessoa, L. (2006). Sustained and transient modulation of performance induced by emotional picture viewing. Emotion 6, 622-634.

Pessoa, L., and Adolphs, R. (2010). Emotion processing and the amygdala: from a "low road" to "many roads" of evaluating biological significance. Nat. Rev. Neurosci. 11, 773-783.

Pessoa, L., Padmala, S., and Morland, T. (2005). Fate of unattended fearful faces in the amygdala is determined by both attentional resources and cognitive modulation. Neuroimage 28, 249-255.

Petrides, M. (2005). Lateral prefrontal cortex: architectonic and functional organization. Philos. Trans. R. Soc. Lond. B Biol. Sci. 360, 781-795.

Petrides, M., Alivisatos, B., Evans, A. C., and Meyer,E. (1993). Dissociation of human mid-dorsolateral from posterior dorsolateral frontal cortex in memory processing. Proc. Natl. Acad Sci. U.S.A. 90, 873-877.

Plutchik, R. (1962). Emotion: A Psychoevolutionary Synthesis. New York, NY: Harper \& Row.

Pochon, J. B., Levy, R., Fossati, P., Lehericy, S., Poline, J. B., Pillon, B., Le Bihan, D., and Dubois, B. (2002). The neural system that bridges reward and cognition in humans: an fMRI study. Proc. Natl. Acad. Sci. U.S.A. 99, 5669-5674.

Polli, F. E., Wright, C. I., Milad, M. R., Dickerson, B. C., Vangel, M., Barton, J. J., Rauch, S. L., and Manoach, D. S. (2009). Hemispheric differences in amygdala contributions to response monitoring. Neuroreport 20, 398-402.

Pourtois, G., Dan, E. S., Grandjean, D., Sander, D., and Vuilleumier, P. (2005). Enhanced extrastriate visual response to bandpass spatial frequency filtered fearful faces: time course and topographic evokedpotentials mapping. Hum. Brain Mapp. 26, 65-79.
Pourtois, G., Vocat, R., N'diaye, K., Spinelli, L., Seeck, M., and Vuilleumier, P. (2010). Errors recruit both cognitive and emotional monitoring systems: simultaneous intracranial recordings in the dorsal anterior cingulate gyrus and amygdala combined with fMRI. Neuropsychologia 48, 1144-1159.

Rich, B. A., Schmajuk, M., Perez-Edgar, K. E., Fox, N. A., Pine, D. S., and Leibenluft, E. (2007). Different psychophysiological and behavioral responses elicited by frustration in pediatric bipolar disorder and severe mood dysregulation. Am. J. Psychiatry 164, 309-317.

Ridderinkhof, K. R., Ullsperger, M. Crone, E. A., and Nieuwenhuis, S. (2004). The role of the medial frontal cortex in cognitive control. Science 306, 443-447.

Robbins, T. W. (1996). Dissociating executive functions of the prefrontal cortex. Philos. Trans. R. Soc. Lond. B Biol. Sci. 351, 1463-1470.

Rolls, E. T., and Grabenhorst, F. (2008). The orbitofrontal cortex and beyond: from affect to decision-making. Prog. Neurobiol. 86, 216-244.

Roseman, I. J. (2008). "Motivations and emotivations: approach, avoidance, and other tendencies in motivated and emotional behavior," in Handbook of Approach and Avoidance Motivation, ed. A. J. Elliot (New York, NY: Psychology Press), 343-366.

Roseman, I. J., and Smith, C. A. (2001). "Appraisal theory: overview, assumptions, varieties, controversies," in Appraisal Processes in Emotion: Theory, Methods, Research, eds K. R. Scherer, A. Schorr, and T. Johnstone (Oxford: Oxford University Press), 3-19.

Rubia, K., Smith, A. B., Taylor, E., and Brammer, M. (2007). Linear agecorrelated functional development of right inferior fronto-striatocerebellar networks during response inhibition and anterior cingulate during error-related processes. Hum. Brain Mapp. 28, 1163-1177.

Savine, A. C., Beck, S. M., Edwards, B. G., Chiew, K. S., and Braver, T. S. (2010). Enhancement of cognitive control by approach and avoidance motivational states. Cogn. Emot. 24 338-356.

Savine, A. C., and Braver, T. S. (2010). Motivated cognitive control: reward incentives modulate preparatory neural activity during task-switching. J. Neurosci. 30, 10294-10305.

Scherer, K. R. (1999). "Appraisal theories," in Handbook of Cognition and
Emotion, eds T. Dalgleish and M. Power (Chichester: Wiley), 637-663.

Schulz, K. P., Clerkin, S. M., Halperin, J. M., Newcorn, J. H., Tang, C. Y., and Fan, J. (2009). Dissociable neural effects of stimulus valence and preceding context during the inhibition of responses to emotional faces. Hum. Brain Mapp. 30, 2821-2833.

Schulz, W. (2002). Getting formal with dopamine and reward. Neuron 36, 241-263.

Shackman, A. J., Salomons, T. V., Slagter, H. A., Fox, A. S., Winter, J. J., and Davidson, R. J. (2011). The integration of negative affect, pain and cognitive control in the cingulate cortex. Nat. Rev. Neurosci. 12, 154-167.

Shackman, A. J., Sarinopoulos, I., Maxwell, J. S., Pizzagalli, D. A., Lavric, A., and Davidson, R. J. (2006). Anxiety selectively disrupts visuospatial working memory. Emotion 6, 40-61.

Shafritz, K. M., Collins, S. H., and Blumberg, H. P. (2006). The interaction of emotional and cognitive neural systems in emotionally guided response inhibition. Neuroimage 31, 468-475.

Shaw, P., Gogtay, N., and Rapoport, J. (2010). Childhood psychiatric disorders as anomalies in neurodevelopmental trajectories. Hum. Brain Mapp. 31, 917-925.

Singh, M. K., Chang, K. D., Mazaika, P., Garrett, A., Adleman, N., Kelley, R., Howe, M., and Reiss, A. (2010). Neural correlates of response inhibition in pediatric bipolar disorder. $J$. Child Adolesc. Psychopharmacol. 20, 15-24.

Smith, E. E., and Jonides, J. (1999). Storage and executive processes in the frontal lobes. Science 283, 1657-1661.

Somerville, L. H., and Casey, B. J. (2010). Developmental neurobiology of cognitive control and motivational systems. Curr. Opin. Neurobiol. 20, 236-241.

Sommer, M., Hajak, G., Dohnel, K., Meinhardt, J., and Müller, J. L. (2008). Emotion-dependent modulation of interference processes: an fMRI study. Acta Neurobiol. Exp. (Wars.) 68, 193-203.

Stuss, D. T., and Alexander, M. P. (2000). Executive functions and the frontal lobes: a conceptual view. Psychol. Res. 63, 289-298.

Taylor, S. F., Welsh, R. C., Wager, T. D., Phan, K. L., Fitzgerald, K. D., and Gehring, W. J. (2004). A functional neuroimaging study of motivation and executive function. NeuroImage 21, 1045-1054. 
Tottenham, N., Hare, T. A., and Casey, B. J. (2011). Behavioral assessment of emotion discrimination, emotion regulation, and cognitive control in childhood, adolescence, and adulthood. Front. Psychol. 2:39. doi:10.3389/fpsyg.2011.00039

Tottenham, N., Tanaka, J. W., Leon, A. C., McCarry, T., Nurse, M., Hare, T. A., Marcus, D. J., Westerlund, A., Casey, B. J., and Nelson, C. (2009). The NimStim set of facial expressions: judgments from untrained research participants. Psychiatry Res. 168, 242-249.

Van Dillen, L. F., Heslenfeld, D. J., and Koole, S. L. (2009). Tuning down the emotional brain: an fMRI study of the effects of cognitive load on the processing of affective images. Neuroimage 45, 1212-1219.

Vanderhasselt, M. A., De Raedt, R., Baeken, C., Leyman, L., and D'Haenen, H. (2009a). A single session of rTMS over the left dorsolateral prefrontal cortex influences attentional control in depressed patients. World J. Biol. Psychiatry 10, 34-42.

Vanderhasselt, M. A., De Raedt, R., Leyman, L., and Baeken, C. (2009b). Acute effects of repetitive transcranial magnetic stimulation on attentional control are related to antidepressant outcomes. J. Psychiatry Neurosci. 34, 119-126.

Vanderhasselt, M. A., Kuehn, S., and De Raedt, R. (2011). Healthy brooders employ more attentional resources when disengaging from the negative: an event-related fMRI study. $\operatorname{Cog} n$. Affect. Behav. Neurosci. 11, 207-216.

Vasic, N., Walter, H., Sambataro, F., and Wolf, R. C. (2009). Aberrant functional connectivity of dorsolateral prefrontal and cingulate networks in patients with major depression during working memory processing. Psychol. Med. 39, 977-987.

Visu-Petra, L., Tincas, I., Cheie, L., and Benga, O. (2010). Anxiety and visual-spatial memory updating in young children: an investigation using emotional facial expressions. Cogn. Emot. 24, 223-240.

Vollm, B., Richardson, P., McKie, S., Elliott, R., Deakin, J. F., and Anderson, I. M. (2006). Serotonergic modulation of neuronal responses to behavioural inhibition and reinforcing stimuli: an fMRI study in healthy volunteers. Eur. J. Neurosci. 23, 552-560.

Vytal, K., and Hamann, S. (2010). Neuroimaging support for discrete neural correlates of basic emotions: a voxel-based meta-analysis. J. $\operatorname{Cog} n$. Neurosci. 22, 2864-2885.

Wager, T. D., Phan, K. L., Liberzon, I., and Taylor, S. F. (2003). Valence, gender, and lateralization of functional brain anatomy in emotion: a meta-analysis of findings from neuroimaging. Neuroimage 19, 513-531.

Wager, T. D., and Smith, E. E. (2003). Neuroimaging studies of working memory: a meta-analysis. Cogn Affect. Behav. Neurosci. 3, 255-274.

Walsh, V., and Pascual-Leone, A. (2003). Transcranial Magnetic Stimulation: A Neurochronometrics of Mind. Cambridge, MA: MIT Press.

Wessa, M., Houenou, J., PaillereMartinot, M. L., Berthoz, S., Artiges, E., Leboyer, M., and Martinot, J. L. (2007). Fronto-striatal overactivation in euthymic bipolar patients during an emotional go/nogo task. Am. J. Psychiatry 164, 638-646.

Whalen, P. J., Bush, G., McNally, R. J., Wilhelm, S., McInerney, S. C., Jenike, M. A., and Rauch, S. L. (1998). The emotional counting Stroop paradigm: a functional magnetic resonance imaging probe of the anterior cingulate affective division. Biol. Psychiatry 44, 1219-1228.

Whitmer, A. J., and Banich, M. T. (2007) Inhibition versus switching deficits in different forms of rumination. Psychol. Sci. 18, 546-553.

Wittfoth, M., Schroder, C., Schardt, D. M., Dengler, R., Heinze, H. J., and Kotz, S. A. (2010). On emotional conflict: interference resolution of happy and angry prosody reveals valence-specific effects. Cereb. Cor tex 20, 383-392.

Yamasaki, H., LaBar, K. S., and McCarthy, G. (2002). Dissociable prefrontal brain systems for attention and emotion. Proc. Natl. Acad. Sci. U.S.A. 99, 11447-11451.
Zhao, X. H., Wang, P. J., Li, C. B., Hu, Z. H., Xi, Q., Wu, W. Y., and Tang, X. W. (2007). Altered default mode network activity in patient with anxiety disorders: an fMRI study. Eur. J. Radiol. 63, 373-378.

Zhou, J., Gao, T., Zhang, Y., Liang, J., Shui, R., and Shen, M. (2011). Losing control in front of a fearful face: the effect of emotional information on cognitive control. Q. J. Exp. Psychol. 64, 1187-1199.

Conflict of Interest Statement: The author declares that the research was conducted in the absence of any commercial or financial relationships that could be construed as a potential conflict of interest.

Received: 30 June 2011; accepted: 24 October 2011; published online: 25 November 2011.

Citation: Mueller SC (2011) The influence of emotion on cognitive control: relevance for development and adolescent psychopathology. Front. Psychology 2:327. doi: 10.3389/fpsyg.2011.00327

This article was submitted to Frontiers in Cognition, a specialty of Frontiers in Psychology.

Copyright (c) 2011 Mueller. This is an open-access article subject to a nonexclusive license between the authors and Frontiers Media SA, which permits use, distribution and reproduction in other forums, provided the original authors and source are credited and other Frontiers conditions are complied with. 